\title{
COMPORTAMENTO ESPACIAL DA DENGUE E SUA RELAÇÃO COM O CLIMA NA REGIÃO METROPOLITANA DE FORTALEZA
}

\author{
Gledson Bezerra Magalhães - gl_mafalhaes@hotmail.com \\ Univ. Fed. do Ceará - Lab. de Climatologia Geográfica e Recursos Hídricos/ UFC \\ Maria Elisa Zanella - elisazv@terra.combr \\ Departamento de Geografia da UFC - Univ. Fed. do Ceará
}

\begin{abstract}
RESUMO: O objetivo desse trabalho constituiu-se em analisar a manifestação da dengue na Região Metropolitana de Fortaleza entre os anos 2001 a 2009, relacionando a quantidade de casos e as incidências da doença com a infestação predial de seu principal vetor e com as características climáticas da região. Para isso, foram adquiridos dados de precipitação, temperatura do ar, infestação da larva do mosquito Aedes aegypti, número de casos e incidência de dengue. Confeccionaram-se mapas, gráficos e estabeleceram-se correlações estatísticas entre as variáveis. Nos anos de grandes quantidades de chuva e homogeneidade espacial da precipitação na quadra chuvosa, a maior quantidade de casos de dengue ocorreu entre um a dois meses depois dos grandes totais pluviométricos, o que não se verifica em anos com poucas precipitações onde a maior quantidade de casos de dengue ocorreu tanto no mês com maior total pluviométrico como em outros meses que tiveram precipitação ou que sucedeu em até 2 meses os picos de chuva. Nos anos em que ocorreram poucos casos de dengue, observou-se uma aleatoriedade espaço-temporal de seus casos, e aparentemente uma menor relação com os elementos atmosféricos. Já em anos de epidemia, nota-se uma relação mensal mais nítida entre número de casos e precipitação, assim como uma maior similaridade temporal no comportamento da dengue entre os municípios. Não se identificou relações entre as amplitudes térmicas mensais com os casos de dengue e de infestação do Aedes aegypti, todavia notou-se que as temperaturas mínimas, médias e máximas são favoráveis a propagação da doença. Apesar das correlações entre a temperatura do ar e os casos de dengue apresentarem resultados negativos, não se pôde afirmar que as menores temperaturas favorecem o aumento de casos de dengue mais do que as temperaturas máximas, devido ao fato de outros fatores, como a precipitação, terem uma influência maior na propagação da doença.
\end{abstract}

Palavras-chave: Climatologia geográfica, dengue, Região Metropolitana de Fortaleza.

SPATIAL BEHAVIOR OF DENGUE AND ITS RELATION TO CLIMATE IN METROPOLITAN AREA OF FORTALEZA

ABSTRACT: The aim of this work consists at analyzing the manifestation of "dengue" at Metropolitan Region of Fortaleza between the years 2001 to 2009, relating the number of cases and incidences of the disease with the infestation of its principal vector and the climatic characteristics of the region. So, were purchased rainfall data, air temperature, the larval infestation of the mosquito Aedes aegypti, the number of cases and incidence of dengue. It was crafted maps, charts and statistical correlations that were established between the variables. Over the years with large amounts of rain and homogeneity of precipitation in the rainy court, the highest number of cases of dengue occurred one to two months after the large rainfall totals, which is not the case in years with low rainfall where the greatest amount of Dengue cases occurred both in the month with the highest total rainfall as in other months they had succeeded or within 2 months the rainfall peaks. In years when there were few cases of dengue, there was a spatial and temporal randomness of their cases, and apparently lower connection with the atmospheric elements. In epidemic years, there is a clearer monthly relationship between number of cases and precipitation as well as a greater temporal similarity in the behavior of dengue among the municipalities. It was not identified relationships between the monthly temperature variations with cases of dengue and Aedes aegypti infestation, however it was noted that minimum, mean and maximum temperatures favor the spread of disease. In despite of the correlations between air temperature and dengue cases show negative results, it cannot be said that the lower temperatures favor the increase of dengue cases more than maximum temperatures, due to the fact that other factors, such as precipitation, have a greater influence on the spread of the disease.

Key-words: Geographical climatology, dengue, Fortaleza Metropolitan Region 


\section{INTRODUÇÃO}

A dengue se tornou um dos principais problemas de saúde pública no mundo tropical, onde sua prevalência cresceu significativamente nas últimas décadas. "A doença tornou-se endêmica em 112 países da África, das Américas, da Região Leste do Mediterrâneo, do Sudeste Asiático e do Pacífico Ocidental" (SINGHI et al., 2007). A Organização Mundial de Saúde (1999) estima que cerca de 2,5 bilhões de pessoas que vivem em áreas tropicais e subtropicais estão em risco, e que ocorram anualmente 50 milhões de casos, com cerca de 550 mil hospitalizados e pelo menos 20 mil mortes, tornado-se a doença mais importante no campo das doenças infecciosas.

No Brasil, a dengue vem ocorrendo de forma continuada, intercalando-se com a ocorrência de epidemias. Siqueira Junior et al. (2005) verificaram que entre 1986 e 1993 foram notificados 294.419 casos, com intervalo de dois anos entre as grandes epidemias, sendo a maioria dos casos ocorrendo de janeiro a maio. Entre 1994 e 2002 foram relatados 2.826 .948 casos, correspondendo a um aumento de incidência de 37 para 454 por 100.000 habitantes. Duas grandes epidemias ocorreram em 1998 e 2002 com 528.388 e 794.219 casos respectivamente.

Em 2009, segundo o Ministério da Saúde (2009), foram registrados 529.237 casos suspeitos de dengue. Foram confirmados 2.271 casos e 154 óbitos por Febre Hemorrágica da Dengue (FHD), e 5.952 casos de dengue com complicação (DCC), com 144 óbitos. No ano anterior ocorreram 4.232 casos de FHD e 17.961 de DCC.

Nesse contexto, o Brasil apresenta-se com grande potencial de proliferação da doença. Especificamente, o Estado do Ceará, localizado próximo à linha do equador ( $2^{\circ} 46^{\prime}$ LAT S / $41^{\circ}$ 24'LONG W e 70 52' LAT S / 370 14' LONG W), recebe uma intensa insolação o ano todo, apresentando temperaturas médias anuais elevadas, característica de uma área de clima tropical. Sua precipitação pluviométrica concentra-se no primeiro semestre do ano, com os maiores totais pluviométricos distribuídos entre os meses de fevereiro a maio, período que se verifica um maior número de casos da dengue.

No Estado do Ceará há casos notificados de dengue desde $1986^{1}$. A partir daí a dengue se manifestou de forma endêmica com o registro de quatro picos epidêmicos nos anos de 1987, 1994, 2001 e 2008, acarretando elevados gastos ao poder público (CEARÁ, 2009). A incidência da dengue tem mostrado uma tendência crescente no Estado a partir da introdução do vírus em 1986.

Entre os anos de 2001 a 2009 o número de casos de dengue na Região Metropolitana de Fortaleza (RMF) representou $64,58 \%$ do total de casos do Estado ${ }^{2}$. A RMF localiza-se no norte/nordeste do Estado do Ceará, entre os meridianos de $38^{\circ} 13^{\prime} 18,3^{\prime \prime}$ e $39^{\circ} 18^{\prime} 00^{\prime \prime}$ W e entre os paralelos de $03^{\circ} 33^{\prime} 6,3^{\prime \prime}$ e $04030^{\prime} 00^{\prime \prime} \mathrm{S}$ (Figura 01). Possui uma área de 5.785,822 $\mathrm{km}^{2}$, abarcando $3,8 \%$ do território cearense e uma população estimada em 3.655.259 habitantes com uma densidade populacional de 631,7 hab/ $\mathrm{km}^{2}$ (BRASIL, 2009). Atualmente é composta por quinze municípios: Horizonte, Pacajus, Chorozinho, São Gonçalo do Amarante, Fortaleza, Caucaia, Maranguape, Pacatuba, Aquiraz, Maracanaú, Pindoretama, Itaitinga, Cascável, Guaiúba e Eusébio, conforme a Lei no 12.989/99.

Silva e Angerami (2008, p. 46) apontam diversos fatores associados à ocorrência das sucessivas epidemias de dengue, incluindo-se "a introdução de novos sorotipos e, possivelmente, genótipos, alterações climáticas (elevação das médias de temperatura, pluviosidade), deficiências dos sistemas de saneamento básico e oferta de água, baixo nível socioeconômico e cultural". Moura (2008) destaca que o crescimento desordenado dos municípios da RMF, reflexo dos fenômenos da urbanização e industrialização resultantes do processo de desenvolvimento do modo de produção capitalista, atrelado a políticas urbanas pontuais e ambientalmente excludentes constitui o tensor de destaque no aumento dos problemas de saúde vinculados a falta de saneamento básico, as alterações climáticas e ao baixo nível socioeconômico e cultural.

Visando entender a relação da dengue com clima da RMF, assim como seu comportamento espaço-temporal, se realizou o presente estudo, visto ser, a RMF, a região do Estado onde se

\footnotetext{
${ }^{1}$ Segundo o Boletim de Saúde de Fortaleza (2003), os primeiros casos de dengue no Ceará surgiram na Praia de Canoa Quebrada (Aracati), em 1986, importados de Nova Iguaçu (RJ).

${ }^{2}$ Cálculo feito com base nos dados da Secretária Estadual de Saúde do Ceará.
} 
concentra o maior número de casos da doença e prioritária no Programa Nacional de Combate a Dengue ${ }^{3}$.

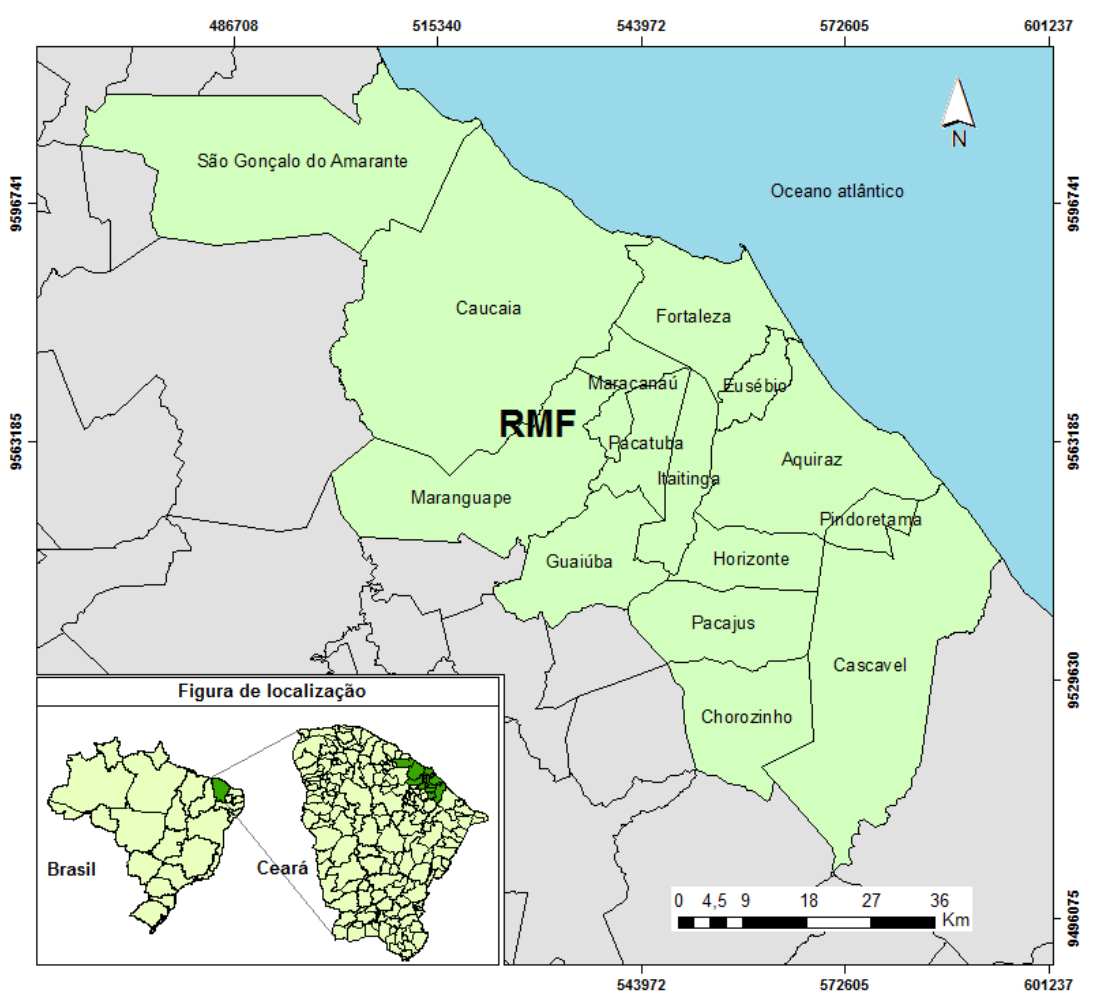

Figura 01 - Localização da Região Metropolitana de Fortaleza

\section{MATERIAIS E MÉTODOS}

Primeiramente realizou-se uma revisão bibliográfica e cartográfica, com vistas à obtenção de aporte teórico sobre a temática desenvolvida e sobre os procedimentos adotados dentro da escala da pesquisa (RMF).

Em seguida foi desenvolvido o banco de dados da pesquisa com o levantamento das incidências mensais, número de casos de dengue mensais e anuais por município e índice de infestação predial (IIP) através da SESA (Secretária de Saúde do Estado do Ceará) e da SMS (Secretária Municipal de Saúde de Fortaleza), para o período de 2001 a 2009. O número de pessoas residentes na RMF foi adquirido por meio de censos demográficos, contagem populacional, projeções e estimativas demográficas do DATASUS e do IBGE. Os dados de precipitação pluviométrica foram adquiridos junto a FUNCEME (Fundação Cearense de Meteorologia e Recursos Hídricos). Já a temperatura do ar foi estimada por meio do método estatístico regressão linear múltipla, utilizando-se a latitude, a longitude e a altitude dos 20 postos pluviométricos utilizados na pesquisa.

Após a tabulação e organização dos dados realizou-se o tratamento geoestatístico dos mesmos, onde foram organizados e analisados no ambiente computacional Microsoft Excel, objetivando a padronização do banco de dados adquirido. Os dados climáticos foram espacializados no software Surfer 8.0 abarcando uma escala anual e sazonal referente a quadra chuvosa.

O Índice de Infestação Predial (IIP), a incidência e os casos de dengue foram espacializados no programa Arc Gis 9.3 na escala anual, com gráficos representativos para os casos no primeiro e segundo semestre de cada ano e dentro ou fora da quadra chuvosa (fevereiro a maio). Para as espacializações utilizou-se a base cartográfica da RMF adaptada da base cartográfica do Ceará, fornecida pelo IBGE (2009). Os diferentes bancos de dados

\footnotetext{
${ }^{3}$ O Programa Nacional de Controle da Dengue (PNCD) encontra-se implantado em todos os municípios brasileiros. No entanto, tendo em vista aspectos populacionais e epidemiológicos foi selecionado um grupo de municípios prioritários, definidos segundo os seguintes critérios: capitais de estados e suas regiões metropolitanas, municípios com população igual ou superior a 50.000 habitantes e municípios com risco de introdução de novos sorotipos de dengue (BRASIL, [200_]).
} 
epidemiológicos da dengue foram organizados de tal forma que as escalas espaço-temporais de análise coincidissem. Para isso estabeleceram-se somas e médias aritméticas diversas para o número de casos, incidência e IIP.

Em seguida ocorreu o estabelecimento de correlações entre a temperatura do ar, pluviosidade e número de casos de dengue. Realizaram-se dois grupos de correlação para cada dupla de variável correlacionada. Tanto nas correlações entre o número de casos de dengue e a precipitação, como na temperatura média do ar com os casos de dengue, foram calculadas sem e com o adiantamento de um mês no número de casos. Procedeu-se dessa forma por acreditar-se que a precipitação e a temperatura do ar continuam influenciando a propagação do Aedes aegypti e da dengue, durante o mês seguinte, como verificado na pesquisa de Lima (2003). Considerando a escala municipal ocorreram correlações mensais entre as variáveis supracitadas para os quinze municípios da RMF, a um nível de significância de 0,05 a fim de verificar estatísticamente a relação entre a incidência de dengue, de seus vetores e dos elementos do clima (temperatura do ar e precipitação).

As correlações foram realizadas por meio do software SPSS 9.0 (Statistical Package for the Social Sciences). Este software permite diferentes análises de dados, teste de hipóteses e criação de modelos de projeção. O método estatístico utilizado foi a "correlação de Pearson" que por meio de seu coeficiente pode-se estimar a força da relação entre duas variáveis.

\section{RESULTADOS}

De acordo com os dados da Secretária de Saúde do Estado, no período de 2001 a 2009 foram confirmados 182.387 casos de dengue no Ceará. Destes, 117.793 ocorreram na RMF, representando $64,58 \%$ do total de casos do Estado para o período.

Os anos com maiores números de casos de dengue na RMF foram 2008, com 36.120 casos e uma incidência de 326,4, seguido de 2006, com 17.837 casos e incidência de 413,9, e o ano de 2001, com 15.300 casos e uma incidência de 310,2. Essas são as maiores epidemias do período analisado, correspondendo a $81 \%, 69,8 \%$ e $59,7 \%$ do total de casos do Ceará respectivamente. O ano de 2004 apresentou o menor número de casos (665) e a menor incidência $(7,9)$, seguido do ano de 2009 com 4.179 casos e uma incidência de 13,4.

A figura 02 apresenta a evolução da dengue na RMF e no Ceará. Nela observa-se que a RMF acompanha a evolução dos casos de dengue do Estado, todavia, ao analisar o número de casos da doença de forma individual em cada município da RMF, notou-se que, exceto para Fortaleza, Horizonte e Eusébio, esse comportamento, em algum dos anos em estudo, não vai seguir o padrão da RMF e do Ceará, o que caracteriza uma dinâmica própria da doença em cada um deles.

Fortaleza é o município com o maior número de casos de dengue, com 104.577 casos para o período analisado, correspondendo $88,77 \%$ do total de casos da RMF, o que influencia no padrão de evolução do número de casos de dengue na RMF e no Ceará. Sua incidência apresenta uma média de 488,9 entre os anos de 2001 a 2009, tendo a menor incidência em 2004 com 25,3 e a maior na epidemia de 2008 com 1368,2. O município de Pindoretama registrou o menor número de casos da doença (229) na série estudada, seguido de Eusébio (297), Itaitinga (331), Chorozinho (323) e Aquiraz (342).

Somente nos anos de 2004 e 2009 não foram registrados casos de dengue em alguns municípios da RMF. Chorozinho, Eusébio, Guaiúba, Pindoretama e São Gonçalo do Amarante não apresentaram casos no ano de 2004. No ano de 2009 a ausência de casos ocorreu nos municípios de Chorozinho, Itaitinga e Pindoretama. 


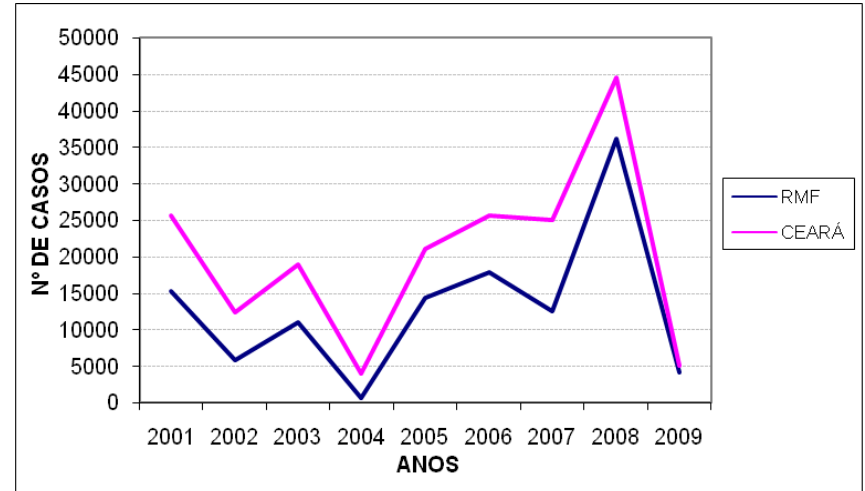

Figura 02 - Gráfico do total de casos de dengue de 2001 a 2009. Fonte de Dados: SESA

A figura 03 apresenta o gráfico da predominância do tipo viral da dengue circundante em cada ano para o Ceará. Como a RMF concentra mais da metade do número de casos do Estado, resolveu-se generalizar as informações pertinentes a circulação viral no Ceará para a RMF. Portanto no ano de 2001 nota-se a atuação dos vírus do tipo 1 e 2, com predominância do vírus do tipo 2. Nos anos de 2002 e 2003 têm-se a presença dos tipos virais 1, 2 e 3, onde no ano de 2002 observa-se a preeminência do tipo 1 e em 2003 do tipo 3. No ano de 2004 foi identificado somente a atuação do tipo 1. De 2006 a 2008, houve a atuação dos vírus do tipo 2 e 3, com predominância do tipo 2 em 2006, e do tipo 3 em 2007 e 2008. No ano de 2009 identificou-se somente o tipo 2 .

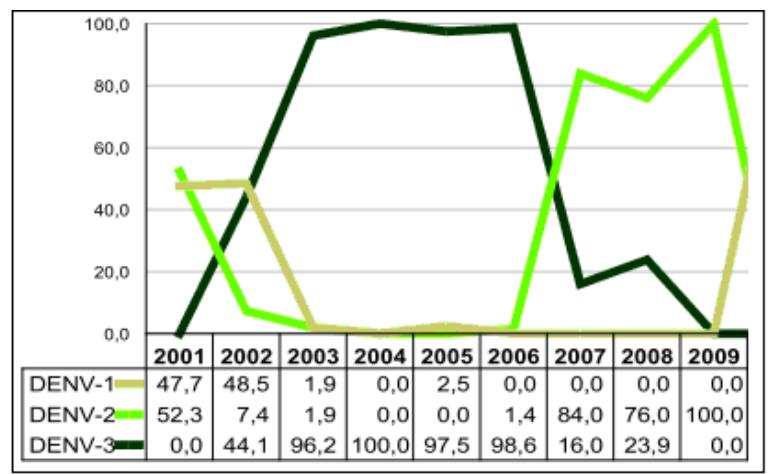

Figura 03 - Gráfico do percentual de isolamento para dengue por sorotipo viral, Ceará, 2001 a 2009. Fonte: Adaptado do informe semanal: dengue - SESA - 01/04/2011.

O pequeno número de casos registrados e a baixa incidência em 2004 e 2009 justificam-se, em parte, pelo pico epidêmico do ano anterior adjacente. O número de casos em 2003, ocasionados pelo vírus do tipo 3, proporcionou uma imunização da população para esse vírus no ano seguinte, onde só foi identificado a presença desse tipo de vírus. O pico epidêmico de 2008, ocasionado em grande parte pelo vírus do tipo 2, gerou um significativo número de pessoas imunizadas a esse tipo viral, o que fez com que o ano de 2009, com a circulação apenas do tipo 2, tivesse um número reduzido de pessoas acometidas pela doença.

No período de 2001 a 2009 o primeiro semestre concentra 74,4\% dos casos de dengue, sendo os meses de abril, maio e junho, os de maiores números de casos (Figura 04). O mês de maio registrou maior quantidade de casos da doença. A partir desse mês os casos vão diminuindo, findando com dezembro como o mês com menores registros.

A quadra chuvosa (meses de fevereiro a maio) concentrou $55,86 \%$ dos casos de dengue. Fora dela, os meses de junho e julho apresentam os maiores números de casos, que se mostraram superiores aos meses de fevereiro e março. As precipitações menos intensas e mais esparsas, que caracterizam os meses de junho e julho; e a influencia da propagação da doença e de seu vetor nos dois meses anteriores, contribuem para o número elevado de casos. 


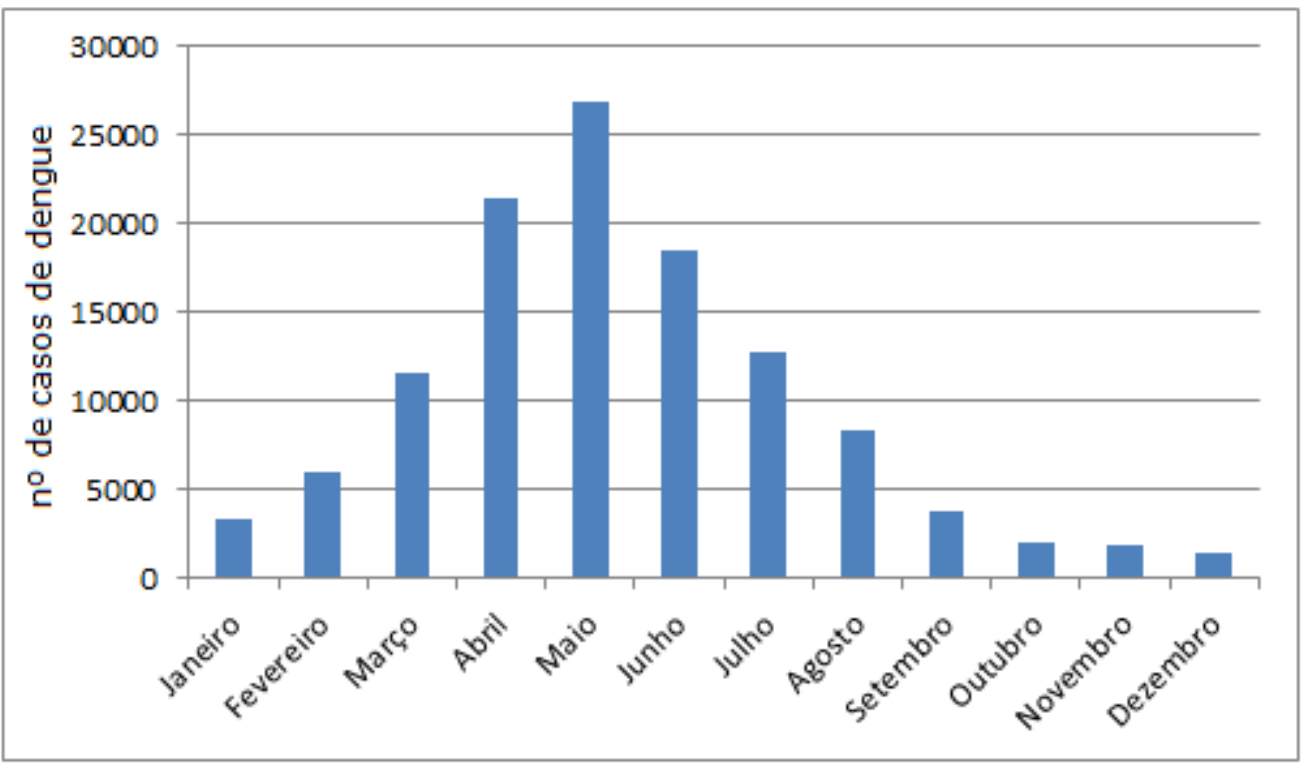

Figura 04 - Casos mensais de dengue entre os anos de 2001 a 2009 na RMF. Fonte de dados: SESA

No ano de 2001, ocorreu a primeira epidemia de dengue do século XXI na RMF. Com 15.300 casos representando $59,7 \%$ de casos do Estado, ocorreram casos de dengue em todos os municípios da RMF, com maior número em Fortaleza. O Primeiro semestre concentrou 80,8\% dos casos, destes $70,1 \%$ ocorreram na quadra chuvosa (Figura $5 \mathrm{~A})^{4}$. O mês de maio apresentou a maior quantidade de casos para todos os municípios exceto para Chorozinho e São Gonçalo do Amarante que tiveram os maiores números em abril. De setembro a dezembro foram registrados os menores números de casos. A incidência de dengue foi maior nos municípios de Fortaleza, Pacajús, Itaitinga, Horizonte e Pindoretama, ultrapassando 300 casos por 100.000 habitantes (Figura 5B). O destaque foi para Horizonte onde se verificou a incidência com 862,9. Já a menor ocorreu em Guaiúba com 89,3. A infestação de Aedes aegypti foi acima de 1 em todos os municípios da RMF com exceção de Pindoretama e Horizonte (Figura 5C). Estes dois municípios, por apresentarem pequena população, tiveram alta incidência de dengue, apesar de um baixo índice de infestação do mosquito e de um reduzido número de casos se comparado com os outros municípios. O IIP foi maior nos $1^{a}$ e $2^{a}$ LIAS (Levantamentos de Índice Amostral) ${ }^{5}$ em todos os municípios. Essas duas LIA's juntas compreendem o primeiro semestre do ano.

Apesar de La Niña moderada e Dipolo do Atlântico neutro, houve baixas precipitações em 12 dos 20 postos pluviométricos estudados, mesmo assim, as poucas e concentradas precipitações corroboraram para uma epidemia de dengue em 2001. A epidemia ocasionada pelos sorotipos 1 e 2, se concentrou principalmente no primeiro semestre do ano, acompanhando o perfil pluviométrico com uma diferença de um mês entre o mês mais chuvoso e o mês com maior quantidade de casos. Os picos de casos de dengue no mês de maio corresponderam à diminuição significativa das precipitações nesse mês, visto que os maiores totais pluviométricos foram nos meses de março e abril. Verifica-se para esse ano um padrão de comportamento da dengue similar em todos os municípios. As figuras 6 e 7 apresentam o ocorrido no município de Horizonte. Nele verificou-se uma clara relação entre a precipitação e os casos de dengue, assim como com o IIP. Os meses de janeiro a agosto apresentam IIP crescentes, tendo a maior infestação em agosto. Apesar de no mês de maio o

${ }^{4}$ Os gráficos de pizza presentes nos mapas deste artigo correspondem a duas informações distintas. A metade superior do gráfico de pizza, que corresponde as cores vermelho-escuro e vermelho-claro, indicam a porcentagem de casos no primeiro e segundo semestre respectivamente, enquanto a parte inferior do gráfico, correspondente as cores azul-escuro e azul-claro, indicam a porcentagem de casos dentro e fora da quadra chuvosa concomitantemente. Dessa forma, apesar do gráfico em pizza apresentar informações aparentemente conjuntas elas devem ser interpretadas de forma distinta, evidenciadas pela variação de intensidade das cores vermelha e azul.

${ }^{5}$ Os LIAs (Levantamento de Índice Amostral) são levantamentos feitos por ciclos anuais. O Ministério da Saúde adota a seguinte estratificação para o IIP ou LIA: <1 (satisfatório); 1 a 2,9 (estado de alerta); $>3$ (risco de surto epidêmico). Não há uma padronização dos LIAs, ficando a cargo de cada município o período de execução de cada levantamento. 
IIP continuar crescendo, o número de casos de dengue e as precipitações decrescem. Isso ocorre devido à condição de progressão reprodutiva do mosquito que em maior quantidade se multiplica até atingir um ápice populacional, mesmo com as condições ambientais sendo cada vez mais desfavoráveis, e decresce devido tanto ao número exacerbado de mosquitos como pela deterioração das condições de reprodução. Não foi observado influência da variação térmica mensal nas variáveis epidemiológicas. As temperaturas médias mensais foram propícias à proliferação da dengue ao longo do ano, fato que se repete em todos os anos estudados.

As correlações entre os casos de dengue e a precipitação em 2001, tiveram apenas um resultado significativo (município de Pacajús), marcando uma correlação de 0,899 para a correlação com o adiantamento de um mês no número de casos de dengue, indicando forte relação positiva da chuva com a dengue nesse município. Relativo às correlações entre número de casos de dengue e temperatura do ar foi observado que apenas o município de Maracanaú, na correlação sem o adiantamento de um mês, apresentou resultado significativo marcando $-0,732$ (correlação alta) para um nível de significância de 0,007. Na correlação com um mês de adiantamento observaram-se resultados significativos para os municípios e Aquiraz, Eusébio, Horizonte, Pindoretama, Caucaia e Maranguape, todos marcando correlações altas com valores negativos. Ressalta-se que as correlações para esse ano se tornaram mais evidentes e estatisticamente significativas quando realizado o adiantamento de um mês no número de casos de dengue.

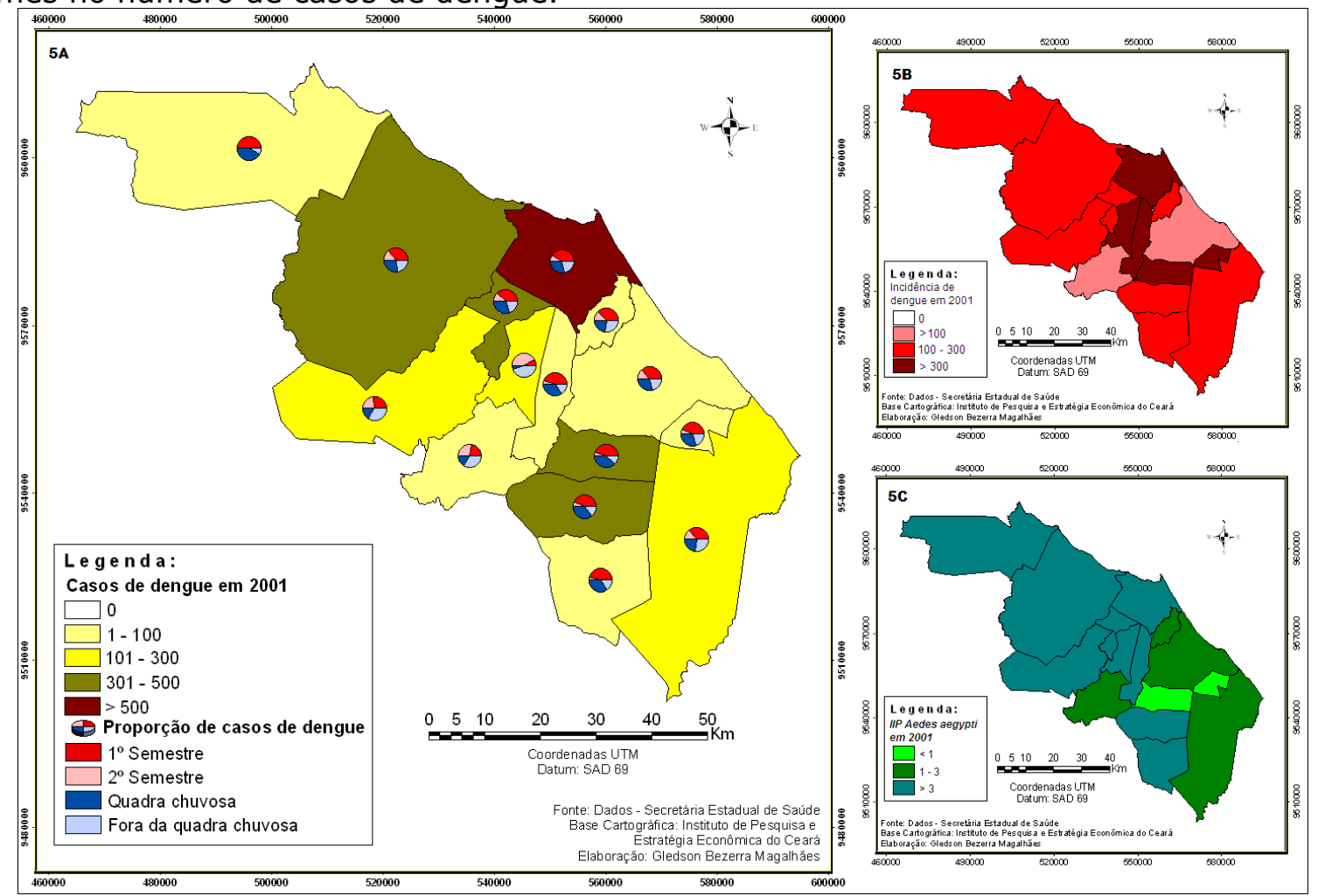

Figura 05 - Mapas do número de casos e incidência de dengue, e índice de infestação predial em 2001

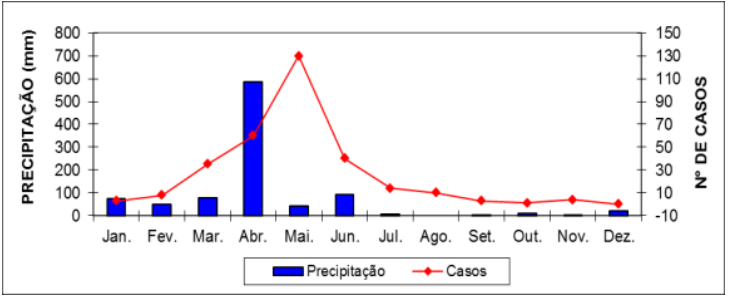

Figura 6 - Precipitação e casos de dengue no município de Horizonte em 2001

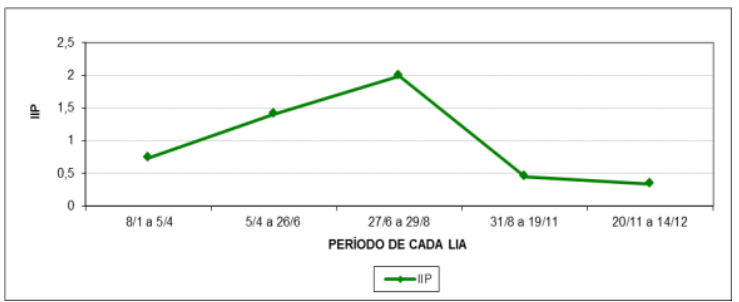

Figura 7 - Índice de Infestação Predial no município de Horizonte em 2001

O ano de 2002 apresentou uma quantidade significativamente menor de casos (5.907) do que o ano anterior. Entretanto, sem uma diferença alarmante, Chorozinho, Cascavel, Pacatuba e 
Guaiúba registraram maior quantidade de casos que no ano de 2001. A circulação dos vírus tipo 1,2 e 3, com destaque para os tipos 1 e 3, não foram suficientes para causar uma epidemia, haja vista a imunização de grande parte da população devido a epidemia de 2001. A quadra chuvosa concentrou $79,5 \%$ de casos dos $70,2 \%$ do primeiro semestre. Todos os municípios apresentaram casos de dengue, com concentração de casos no primeiro semestre, em especial na quadra chuvosa, exceto São Gonçalo do Amarante que registrou mais casos no segundo semestre (Figura 8A). Esse município apresentou 21 casos de dengue, desses, 16 foram registrados no segundo semestre, sendo 11 casos no mês de julho. Os meses de fevereiro e março registraram a maior quantidade de casos na RMF com 1.021 e 1.148 respectivamente, e dezembro teve o menor número de casos confirmando, 161 . O município de Fortaleza, apresentando a maior quantidade de casos, foi o único a registrar acima de 500 casos. Esse fato se repete em todos os anos, devido a sua superioridade populacional, concentrando $70,2 \%$ da população de sua região metropolitana, reforçando a propagação da dengue em seus limites, visto que há uma relação direta entre a densidade demográfica e a propagação da dengue. Pacatuba apresentou a maior incidência do ano com 425,4. Oito municípios tiveram incidência abaixo de 100, e seis municípios apresentaram entre 101 a 300 (Figura 8B). As maiores infestações foram em São Gonçalo do Amarante, Caucaia e Maranguape, os demais municípios registraram infestações abaixo de 3 (Figura 8C).

Apesar do total pluviométrico deste ano ter sido maior que o do ano anterior, apenas nos municípios supracitados ocorreu aumento de casos de dengue. Essa relação se coloca pela dinâmica peculiar da doença em cada município, onde apesar de em alguns anos e entre alguns municípios se verificar um padrão de comportamento da dengue, ocorre especificidades, haja vista que nesse padrão há generalizações. São Gonçalo do Amarante teve mais registros de casos de dengue no segundo semestre, principalmente no mês de julho. De acordo com as figuras 9 e 10 a evolução no número de casos de dengue não corresponde à evolução da precipitação e do IIP. Este último, apesar de apresentar um decréscimo contínuo até novembro, registrou as maiores infestações no primeiro semestre. Quando se têm pequenas quantidades de casos de dengue nos municípios, observa-se uma aleatoriedade temporal dos casos, não existindo, geralmente, uma ligação com a sazonalidade da precipitação e podendo ou não haver relação com o IIP, o que vai depender de outros fatores, como a circulação do vírus.

Para o ano de 2002, nas correlações entre precipitação e a quantidade de casos de dengue obteve-se o maior número de resultados significativamente estatísticos nos cálculos com um mês de adiantamento no número de casos da doença. Enquanto na correlação sem o adiantamento seis municípios apresentaram resultados significativos; na correlação com adiantamento nove municípios apresentaram resultados significativos estatisticamente. Todas as correlações foram positivas e apresentaram variações de moderada a muito alta. Referente às correlações do número de casos com a temperatura do ar, observa-se, assim como no ano de 2001, a maior quantidade de resultados significativos nas correlações com o adiantamento de um mês, com 4 resultados significativos, enquanto as correlações sem o adiantamento tiveram 2 resultados significativos estatisticamente. Todas elas foram negativas variando entre correlações moderadas a muito alta. 

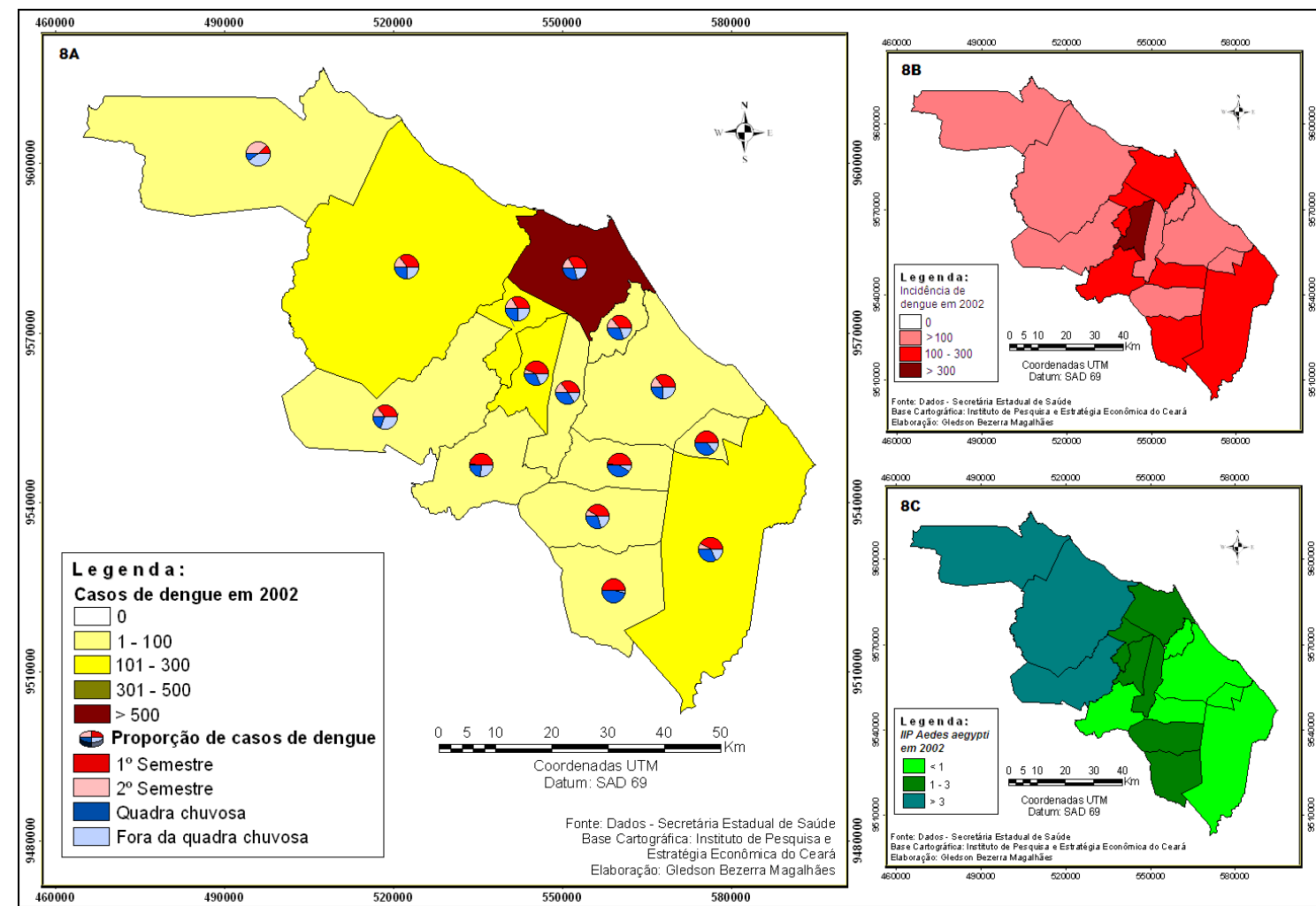

Figura 08 - Mapas do número de casos e incidência de dengue, e índice de infestação predial em 2002

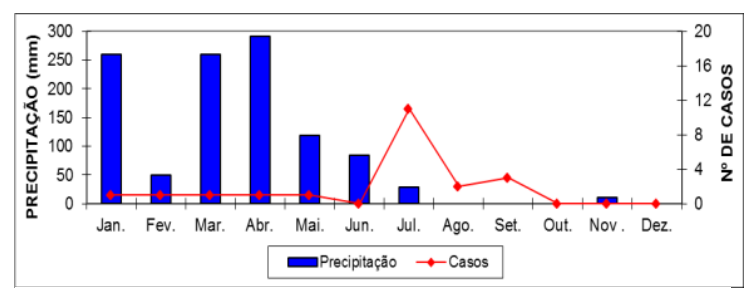

Figura 9 - Precipitação e casos de dengue no município de São Gonçalo do Amarante em 2002

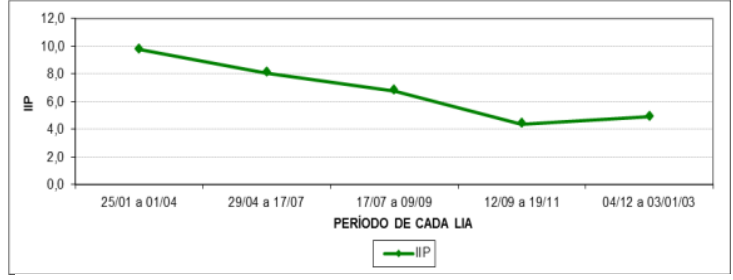

Figura 10 - Índice de Infestação Predial no município de São Gonçalo do Amarante em 2002

Os outros municípios apresentam um comportamento similar ao exposto nas Figuras 11 e 12 para o município Cascavel no ano de 2002, onde se observou que os dois picos de casos de dengue ocorreram nos meses posteriores aos meses de janeiro e abril, que registraram totais pluviométricos maiores que os meses adjacentes. O IIP acompanha a quadra chuvosa tendo sua maior infestação entre os meses de março e maio, decrescendo em seguida, para ter um aumento no final de outubro até dezembro, quando se verifica precipitações nos postos pluviométricos de Caucaia, Cascavel-Cristais, Eusébio, Maracanaú, Pacajús e Pindoretama.

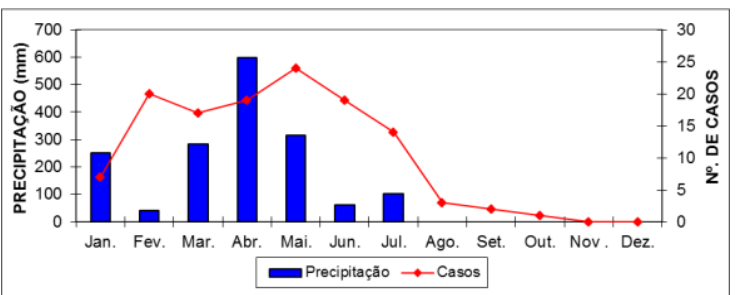

Figura 11 - Precipitação e casos de dengue no município de Cascavel em 2002

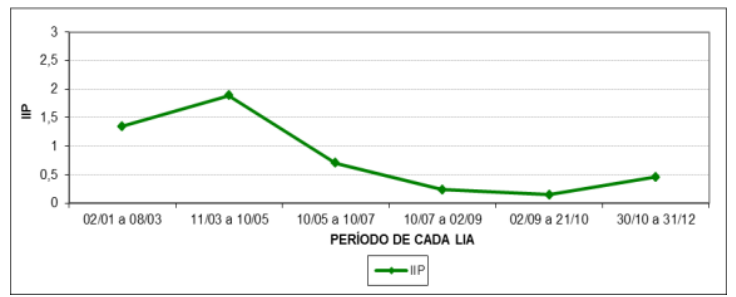

Figura 12 - Índice de Infestação Predial no município de Cascavel em 2002

A quantidade de casos volta a subir em 2003 registrando um total de 10.953 e incidência 179.7. O primeiro semestre concentrou $88,3 \%$ dos casos. Destes $78 \%$ ocorreram na quadra chuvosa, com destaque para maio com 2.900 casos. No mês de dezembro verificou-se a menor quantidade de casos (13). Fortaleza teve 9.012 casos e uma incidência de 399.4, 
sendo o município que apresentou os maiores valores para essas variáveis. São Gonçalo do Amarante apresentou uma incidência de 29,3 e 11 casos de dengue, sendo o município com menores valores, apesar de apresentar o maior IIP da RMF. Isso pode ter ocorrido pela baixa circulação dos vírus da dengue naquele município. Fortaleza e Maracanaú apresentaram mais de 500 casos. Caucaia, Maranguape, Pacajús e Cascavel tiveram entre 101 e 300 casos. Os outros municípios tiveram até 100 casos (Figura 13A). São Gonçalo do Amarante, Itaitinga, Eusébio, Pindoretama e Pacajús foram os municípios onde a incidência não ultrapassou 100 casos por 100.000 habitantes (Figura 13B). Os municípios da porção oeste da RMF apresentaram infestação acima de $1 \mathrm{com}$ destaque para São Gonçalo do Amarante que teve uma infestação de 3.6 (Figura 13C). Apesar da RMF ter registrado mais casos de dengue do que no ano anterior, Cascavel, Pacatuba e São Gonçalo do Amarante tiveram menos casos que no ano de 2002.

No ano de 2003 se observou significativas diferenças de precipitação ao longo da RMF. Postos pluviométricos marcaram tipologia climática de muito chuvoso, assim como houve postos com valores que demonstravam um ano muito seco. Uma significativa variação espacial na incidência de dengue também foi observada para o mesmo ano, todavia não se encontrou nenhum padrão de relação entre a tipologia climática e a incidência de dengue, apesar de $69 \%$ dos casos de dengue terem ocorrido na quadra chuvosa. A quadra chuvosa apresentou a partir de março uma diminuição dos totais pluviométricos, e no mesmo período verifica-se um aumento do número de casos de dengue para Fortaleza, mostrando uma relação inversa entre a quantidade de casos e o total de chuva. Entretanto ressalta-se que no período da quadra chuvosa, grandes quantidades de chuva podem ser prejudiciais a proliferação do Aedes aegypti. O maior número de casos de dengue em maio é favorecido pela diminuição da precipitação que teve seu pico nos meses de março e abril. A quantidade crescente de chuva de janeiro a abril resulta na criação de ambientes propícios ao aumento da infestação pelo vetor da dengue até o ponto que essa quantidade não extermine os criadouros do mosquito, 0 que favoreceria a diminuição na quantidade de casos. Nos outros municípios as maiores quantidades de casos de dengue vão variar entre os meses de fevereiro a maio. O IIP apresentou seus maiores valores na $1^{a}$ e $2^{a}$ LIAs, correspondendo aos meses do primeiro semestre, acompanhando os casos de dengue e as chuvas do primeiro semestre. Em São Gonçalo do Amarante foi verificado o maior IIP, entretanto, apresentou somente 11 casos de dengue no ano, todos no primeiro semestre, onde também foram verificados os maiores índices de infestação do mosquito. Os casos de dengue em Aquiraz acompanham uma evolução similar aos outros municípios, variando apenas em número de casos e os meses de maior quantidade dentro da quadra chuvosa. Na figura 14, para Aquiraz, observa-se uma concentração de casos no primeiro semestre com picos em maio e junho quando as precipitações da quadra chuvosa começam a diminuir. O IIP do município, ilustrado na figura 15, acompanha a sazonalidade da precipitação, com seu maior valor na $2^{\mathrm{a}}$ LIA compreendendo a diminuição das chuvas da quadra chuvosa.

Nas correlações entre precipitação e número de casos de dengue no ano de 2003 o maior número de resultados significativos estatisticamente ocorreu nos cálculos sem o adiantamento de um mês nos números de casos, totalizando nove municípios com correlações positivas significativas, enquanto que com o adiantamento de um mês se observa cinco municípios, todos demarcando correlações moderadas a muito altas. O oposto ocorre com a correlação entre o número de casos de dengue e a temperatura do ar, onde se verifica a maior quantidade de resultados estatisticamente significativos nas correlações com um mês de adiantamento no número de casos, totalizando 7 municípios, enquanto apenas 2 municípios apresentaram correlações significativas nos cálculos sem o adiantamento de um mês na quantidade de casos, todos negativos, variando entre correlações altas e muito altas. 


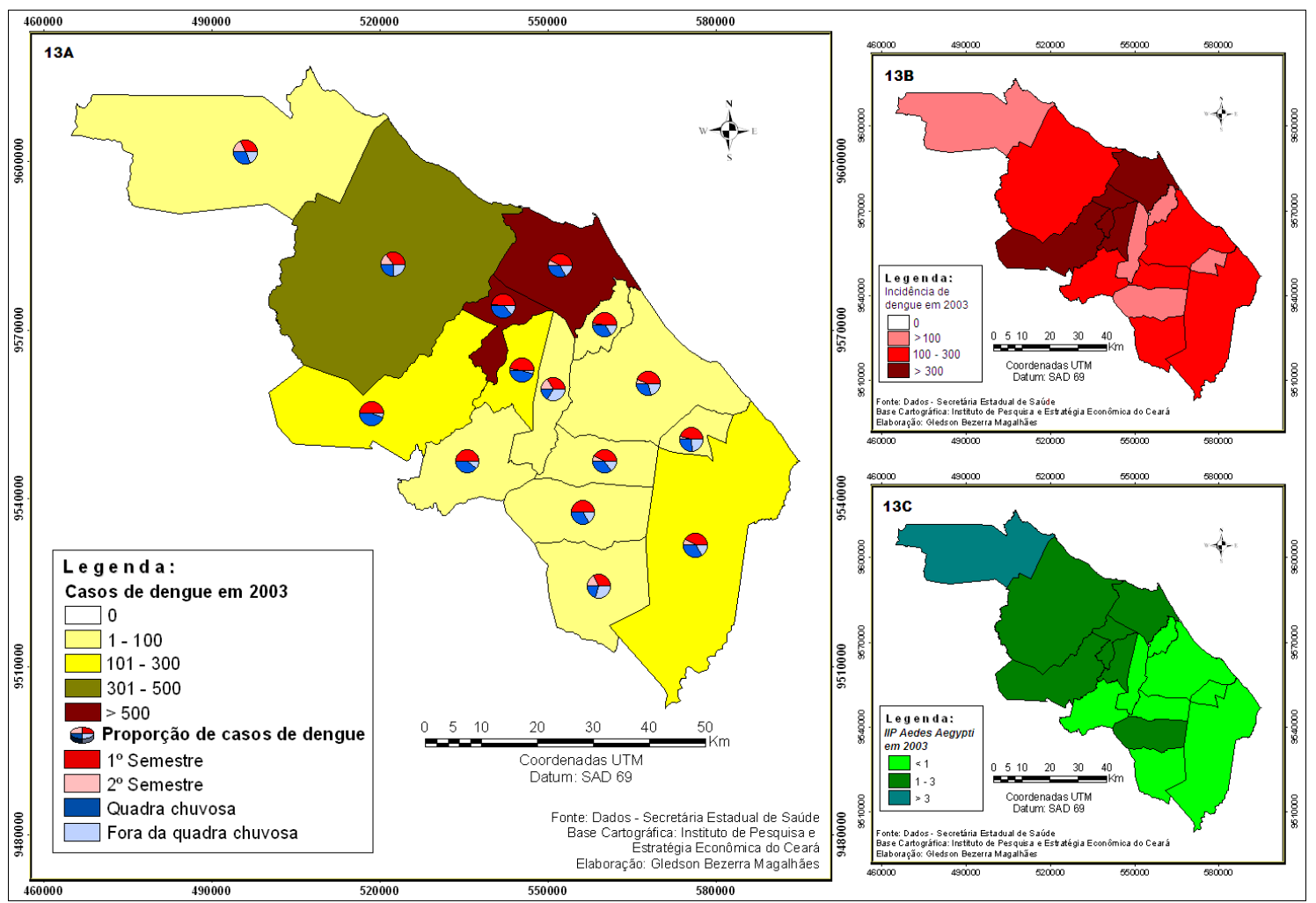

Figura 13 - Mapas do número de casos e incidência de dengue, e índice de infestação predial em 2003

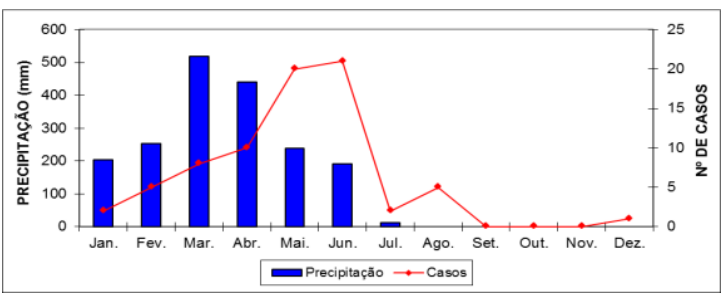

Figura 14- Precipitação e casos de dengue no município de Aquiraz em 2003

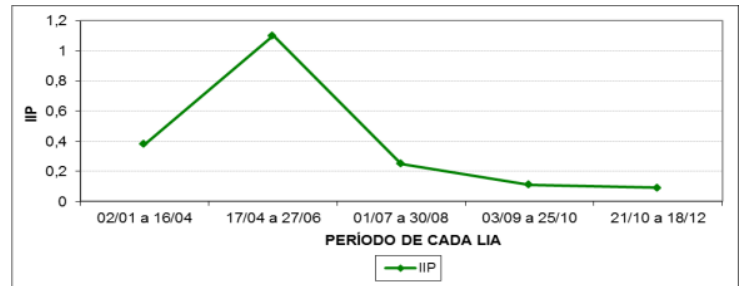

Figura 15 - Índice de Infestação Predial no município de Aquiraz em 2003

Com a circulação apenas do vírus tipo 3, o ano de 2004 apresentou a menor quantidade de casos de dengue entre os anos analisados. Essa redução de casos verificou-se em todo o Brasil como mostra o boletim da semana 14 / 2005 divulgado pela SVS - Secretaria de Vigilância em Saúde, do Ministério da Saúde. Segundo esse boletim, em 2004 foram notificados 112.918 casos, o que representa uma redução de $67,4 \%$ quando comparado ao ano de 2003. O Acre foi o único estado a registrar crescimento da doença nesse período. A região Nordeste apresentou o maior índice de redução da doença, $81,46 \%$. Nesse contexto a RMF apresentou 665 casos, uma redução de $94 \%$ em relação ao ano anterior, com $83 \%$ dos casos no primeiro semestre, sendo $73 \%$ na quadra chuvosa, com destaque para fevereiro com 252 casos. Dezembro foi o mês com menos casos, sendo Fortaleza o único município que registrou casos esse mês (11 casos). Fortaleza concentrou 90\% dos casos da RMF em 2004, sendo o único município a registrar acima de 100 casos. Chorozinho, Pindoretama, São Gonçalo do Amarante, Guaiúba e Eusébio, não apresentaram casos de dengue nesse ano (Figura 16A). Itaitinga foi o único município dos que se verificaram casos de dengue, que não apresentou casos no primeiro semestre, tendo registrado apenas um caso em setembro. Houve incidência acima de 100 somente em Fortaleza (Figura 16B) e o IIP não ultrapassou 3 em nenhum dos municípios (Figuras 16C).

A pequena quantidade de casos em 2004 pode ter sido favorecida pelas baixas precipitações ocorridas na RMF, ocasionadas pela configuração do El Niño e pela positividade do Dipolo do Atlântico. Nenhum dos postos pluviométricos analisados registrou precipitações suficientes para classificar o ano como chuvoso ou muito chuvoso. O que se verificou foram tipologias climáticas de ano normal a muito seco. Logicamente, outros fatores além da precipitação 
estão envolvidos no processo de propagação da doença, todavia, a ausência de chuvas no ano pode ter diminuído as chances de ambientes propícios ao desenvolvimento das larvas de Aedes aegypti. Mesmo com baixas precipitações a maior quantidade de casos de dengue foi verificada no primeiro semestre em particular na quadra chuvosa. Entretanto, ao contrário dos anos anteriores, os maiores números de casos ocorreram em janeiro e fevereiro, com 119 e 252 respectivamente, perfil ocasionado principalmente pelo maior número de casos em Fortaleza. As chuvas para esse ano também foram maiores nesses dois meses, com total de precipitação além do normal para o mês de janeiro, sendo o mês com maior precipitação do ano, declinando em fevereiro e voltando a subir no mês posterior. Os baixos IIPs verificados exprimem uma fragilidade no ciclo reprodutivo do mosquito neste ano. Os IIPs mais elevados foram verificados na $1^{a}$ e $2^{a}$ LIAs, abarcando o primeiro semestre. As figuras 17 e 18 exprimem o que ocorreu em Aquiraz em 2004, que apresentou uma tipologia climática de total pluviométrico normal. Nas figuras podemos observar que os meses de fevereiro e abril apresentam maiores números de casos que seus meses anteriores ao mesmo tempo em que as precipitações desses meses anteriores são maiores que fevereiro e abril. Nos meses de junho a agosto ocorreram precipitações, todavia não foram registrados números de casos.

Nas correlações entre a precipitação e o numero de casos para o ano de 2004 houve apenas um resultado significativo e foi no município de Fortaleza, que apresentou um nível de significância de 0 e uma correlação muito alta $(0,874)$ com o adiantamento de um mês nos casos de dengue. A correlação dos casos de dengue com a temperatura foi significativa somente para Maracanaú nos dois tipos de correlação. Verificou-se um maior resultado ($0,804)$ na correlação com adiantamento, enquanto que a sem adiantamento marcou $-0,785$, sendo os níveis de significância iguais $(0,003)$.
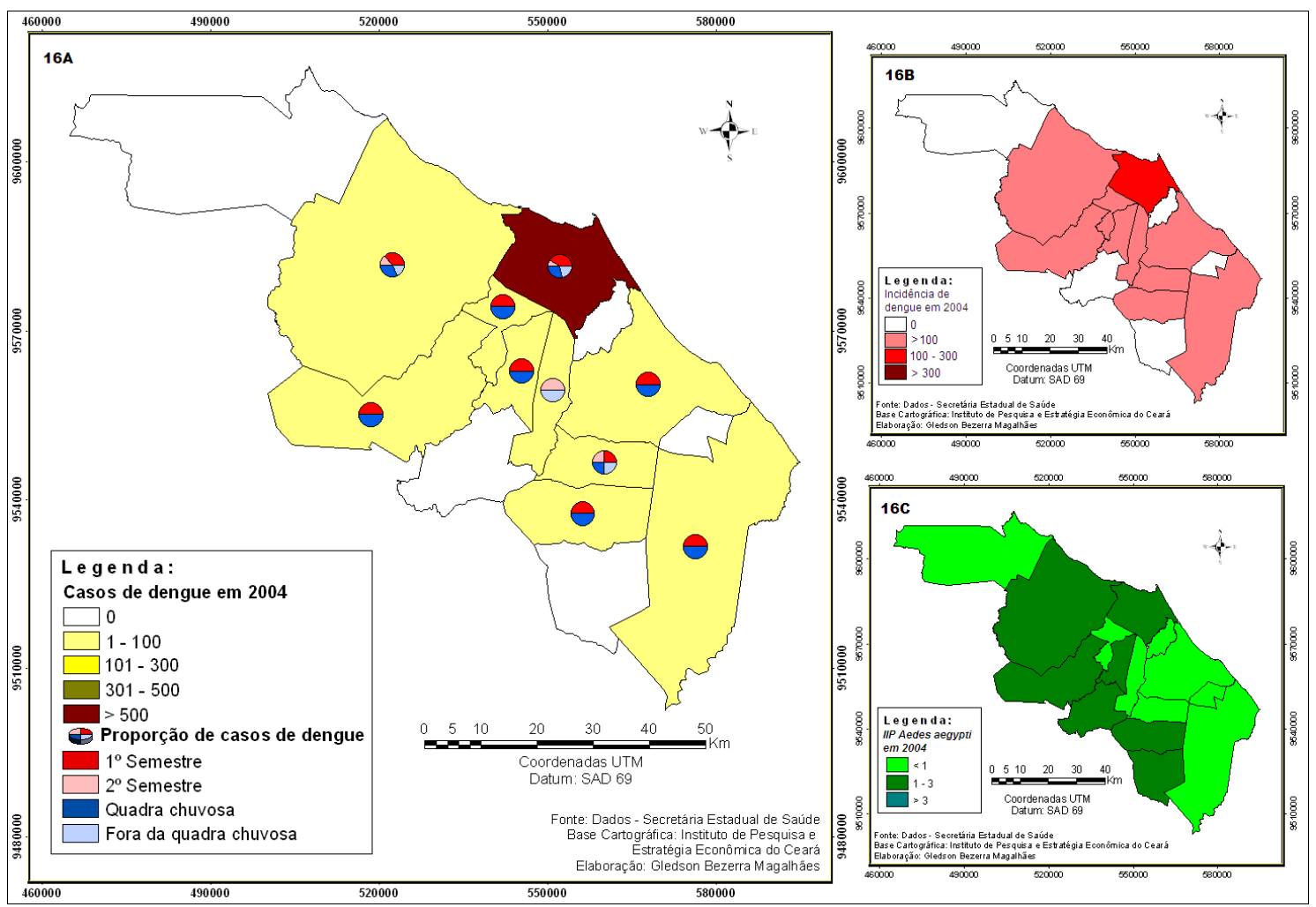

Figura 16 - Mapas do número de casos e incidência de dengue, e índice de infestação predial em 2004 


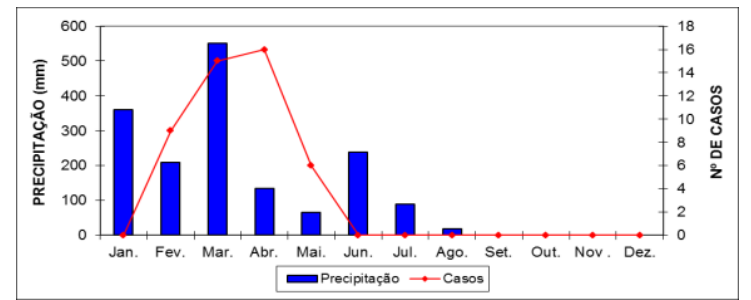

Figura 17- Precipitação e casos de dengue no município de Aquiraz em 2004

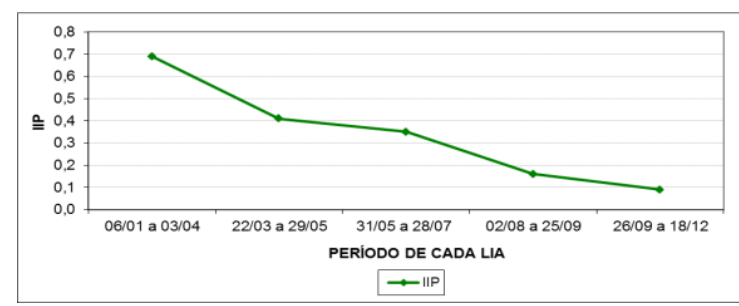

Figura 18 - Índice de Infestação Predial no município de Aquiraz em 2004

No ano de 2005 foram confirmados 14.365 casos de dengue, representando um aumento de $95.4 \%$ em relação ao ano anterior. O número de casos no primeiro semestre foi de 4.049 , representando apenas $28 \%$ do total de casos. Dos anos estudados, 2005 foi o que apresentou, em todos os municípios, mais casos de dengue no segundo semestre do que no primeiro, com exceção de Maracanaú que registrou no primeiro semestre 272 casos e no segundo 207 (Figura 19A). O mês com maior número de casos foi julho com 4.112 casos, já janeiro teve a menor quantidade de casos com 53. Eusébio, Itaitinga, Pindoretama e Guaiúba não registraram nenhum caso de dengue na quadra chuvosa, período em que se verificou a maior quantidade de casos da doença entre os anos analisados. Caucaia e Fortaleza foram os municípios que apresentaram maior quantidade de casos com 616 e 11.776, para uma incidência de 202,7 e 485,8 respectivamente. Sete municípios tiveram incidência acima de 300, sendo as maiores registradas em Chorozinho e Horizonte, com 544,65 e 514,9 respectivamente. As menores incidências foram verificadas em Pindoretama, Eusébio, Aquiraz e Maranguape. Somente Chorozinho apresentou um IIP acima de 3, enquanto Eusébio, Aquiraz, Pindoretama, São Gonçalo do Amarante, Horizonte e Cascavel tiveram IIP inferior a 1 , entretanto esses três últimos municípios apresentaram incidências acima de 300 casos por 100.000 habitantes (Figura 19B e 19C).

Com as condições atmosféricas de mesoescala similares ao ano de 2004, no ano de 2005 foi registrado um total de precipitação inferior ao ano anterior, sendo o ano mais seco da série estudada, todavia verificou-se um aumento de $95,4 \%$ no número de casos de dengue, ocasionados pelos vírus tipo 1 e 3 . A maior quantidade de casos no segundo semestre, representando $72 \%$ dos mesmos, retrata um comportamento atípico do perfil epidemiológico da doença. Julho, agosto e setembro tiveram o maior número de casos, e as precipitações concentraram-se na quadra chuvosa se estendendo até junho, como mostra a figura 20 para o município de Maranguape. O ano de 2005 foi um ano de poucas chuvas, com 18 postos pluviométricos, dos 20 observados, marcando uma tipologia de ano seco a muito seco. Este ano, mais que em 2004, concentrou $79,5 \%$ de sua precipitação na quadra chuvosa, demarcando, mesmo com poucas chuvas, uma concentração significativa nesse período. De forma geral, o regime temporal da precipitação teve um comportamento típico em todos os municípios. O ocorrido em Maranguape representa o que ocorreu na RMF onde observa-se o aumento do IIP na $3^{a}$ LIA, que abrange desde o final de maio até julho. Já na $4^{a}$ LIA nota-se uma pequena diminuição do IIP. Neste ano o IIP teve baixa variação entre as LIAs, o que retrata um perfil temporal atípico do mosquito não seguindo a sazonalidade dos outros anos estudados (Figura 21). Levanta-se a possibilidade de, em termos de precipitação, pelo ano de 2004 se configurar como um ano de tipologia climática normal, e 2005 se configurar um ano seco, ter ocorrido o aumento no armazenamento de água por parte da população, durante principalmente o final do primeiro semestre, devido à diminuição das já poucas chuvas ocorridas na quadra chuvosa, gerando ambientes propícios a procriação do Aedes aegypit e favorecendo a circulação viral, que para esse ano foi bem mais significativa para o vírus tipo $3^{6}$. Nelas observou-se a ausência de casos nos quatro primeiros meses, indo aumentar no final da quadra chuvosa alcançando a maior quantidade no segundo semestre, quando se verificam os maiores números de casos. O IIP apresenta maiores valores na $3^{a}$ LIA compreendendo o final do primeiro semestre e início do segundo, quando se observa um aumento significativo no número de casos de dengue.

\footnotetext{
${ }^{6}$ Ressalta-se que a pesquisa trabalhou com dados agregados, logo não é intenção do estudo justificar o comportamento da dengue pela chuva ou por outro elemento climático, todavia cabe-se nesse quadro apontar possibilidades, que mesmo não verificáveis, traz à tona a dimensão complexa do que é a epidemiologia da dengue.
} 
O ano de 2005 apresentou correlações significativas entre os casos de dengue e a precipitação somente para as correlações com adiantamento de um mês no número de casos. Verificaramse apenas os municípios de Horizonte e Guaiúba com resultados significativos, apresentando 0,631 e -0,632 respectivamente. Ao contrário do que se verificam para os outros anos, os valores negativos das correlações acima são devido a uma excepcionalidade da dengue dentro do período analisado, onde o maior número de casos de dengue ocorreu nos meses de julho, agosto e setembro, meses com poucas chuvas. Em Horizonte e Guaiúba os casos de dengue começaram a surgir nos meses de junho e julho respectivamente. $O$ mês de junho findou 0 término das chuvas nesse ano. A concentração de chuvas no mês de maio pode ter contribuído para o aumento da infestação do Aedes aegypti nos meses de junho e julho. Horizonte e Guaiúba tiveram respectivamente um IIP 0,80 e 3,06 para os meses de junho e julho, meses estes com os maiores IIPs do ano. Ressalta-se que o ano de 2005 teve uma tipologia climática de ano muito seco, o que pode ter provocado a dinâmica diferenciada do Aedes aegypti. Com o aumento dos reservatórios de água o mosquito pode ter se proliferado com maior facilidade. Também se observou a maior quantidade de casos nos meses de maior IIP, correspondendo aos primeiros meses que sucedem o término do período chuvoso. Esse fato verifica-se principalmente em meio rural onde ocorre armazenamento de água na estação seca (RODHAIN e ROSEN, 1997; HALSTEAD, 1997; GLUBER, 2002). As correlações entre a temperatura do ar e os casos de dengue tiveram maiores valores significativos na correlação sem o adiantamento de um mês e seguem o padrão nos anos anteriores marcando correlações negativas que variam de moderada a muito alta.
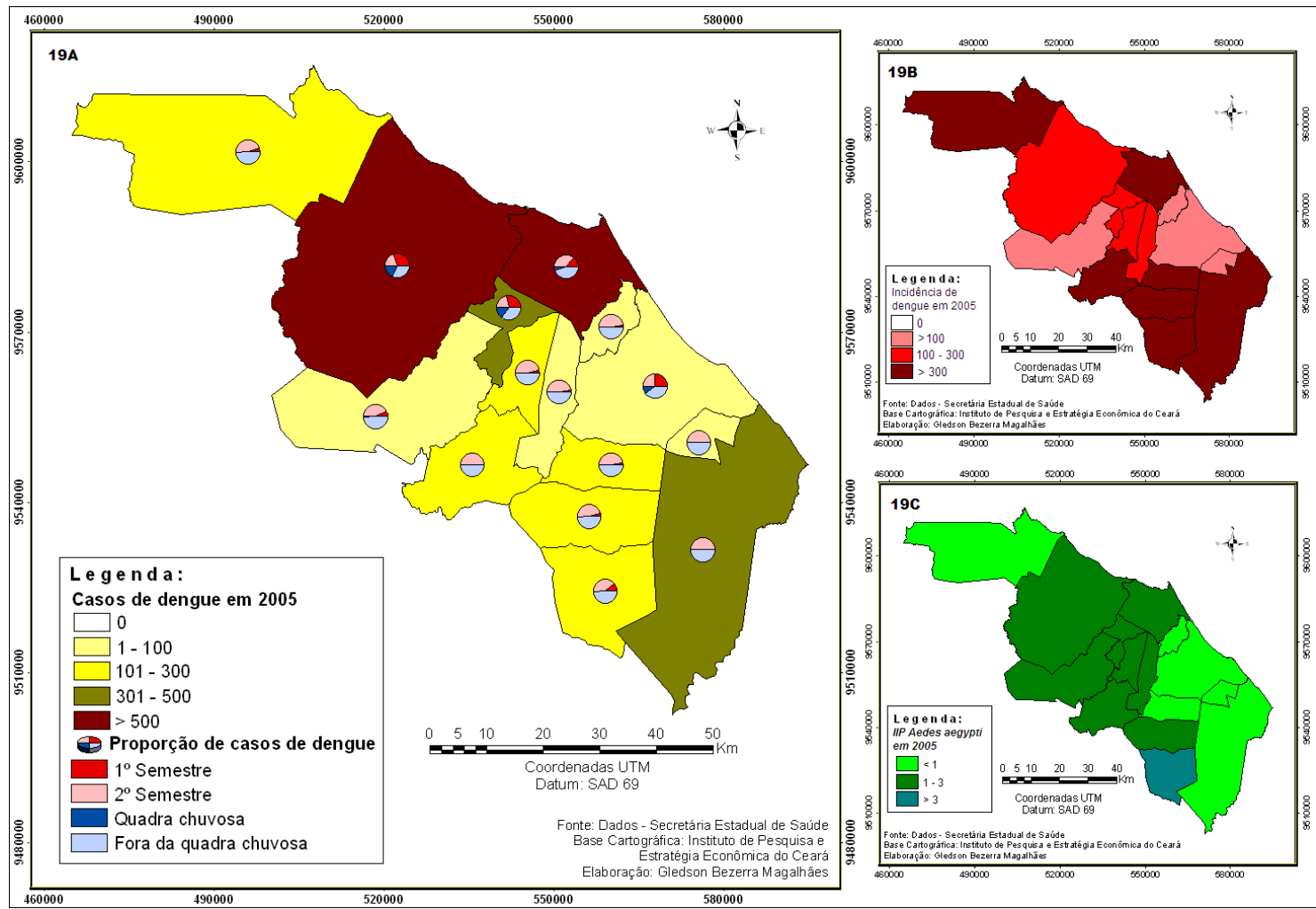

Figura 19 - Mapas do número de casos e incidência de dengue, e índice de infestação predial em 2005

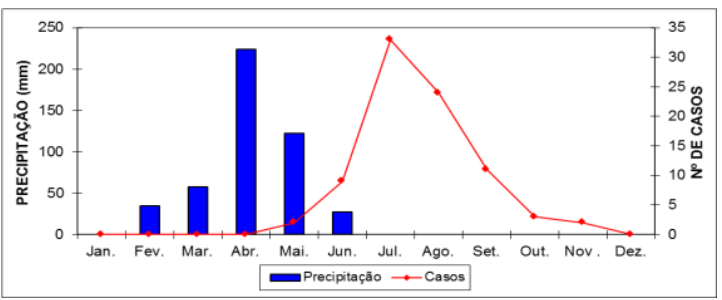

Figura 20 - Precipitação e casos de dengue no município de Maranguape em 2005

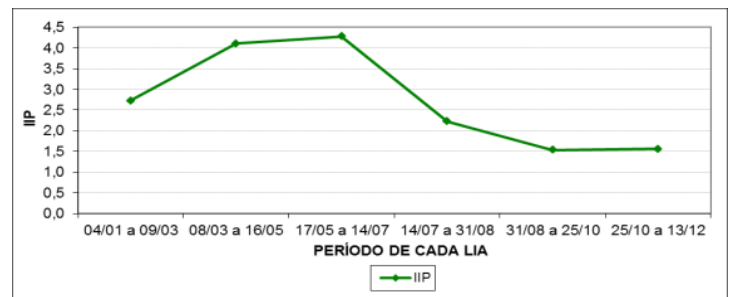

Figura 21 - Índice de Infestação Predial no município de Maranguape em 2005 
O ano de 2006 registrou 17.837 casos, dos quais 10.975 ocorreram no primeiro semestre, correspondendo a $61,5 \%$ dos casos, destes $57 \%$ na quadra chuvosa. O mês de junho teve a maior quantidade de casos, com 4.329 seguido do mês de maio com 4.060 casos. Dezembro apresentou a menor quantidade de casos, 103. Todos os municípios tiveram casos confirmados de dengue, com Fortaleza e Cascavel apresentando os maiores números, registrando 15.865 e 420 casos respectivamente. Sete municípios tiveram abaixo de 101 casos, com destaque para Chorozinho e Aquiraz, com os menores números tiveram apenas 12 e 18 casos. Chorozinho foi o único município deste ano que teve maior quantidade de casos no segundo semestre, registrando 9 casos (Figura 22A). Quatro municípios apresentaram IIP abaixo de 1 e os maiores IIPs foram em Caucaia, Pacatuba e Chorozinho. Destes somente Pacatuba apresentou uma incidência acima de 300 (Figuras 22B e 22C). São Gonçalo do Amarante, Caucaia, Maranguape, Aquiraz, Pacajus e Chorozinho apresentaram as menores incidências e a maior foi em Guaiúba com 990,7 .

Em 2006, apesar do Dipolo do Atlântico estar desfavorável as chuvas, a atuação da La Niña no início da quadra chuvosa garantiu maiores precipitações que as dos dois anos anteriores, caracterizando um ano normal a chuvoso. Verifica-se também um aumento de $20 \%$ dos casos de dengue em relação a 2005, ocasionado pelos vírus do tipo 2 e principalmente do tipo 3, com a maioria deles acorrendo no primeiro semestre, em particular na quadra chuvosa. A maior quantidade de casos em maio e junho acompanha o início da diminuição das precipitações que teve seu pico em abril, perfil obtido quando se inclui Fortaleza no total de casos. Desconsiderando Fortaleza no total de casos, abril e maio concentram a maior quantidade deles, acompanhando o regime pluviométrico. O mês de dezembro teve a menor quantidade de casos, seguindo o padrão da maioria dos anos. Nesse mês registrou-se precipitações em 9 dos 20 postos pluviométricos analisados da RMF, típico de sistemas atmosféricos com pouca abrangência espacial como os Complexos Convectivos de Mesoescala. As figuras 23 e 24 mostram, para Cascavel, um aumento de casos de dengue na quadra chuvosa acompanhando a evolução das precipitações, e do IIP. Esse comportamento ocorre em todos os municípios da RMF, exceto em Fortaleza onde se verifica o adiantamento de um mês no maior número de casos se comparado com os outros municípios.

Os anos de 2006 a 2009 apresentaram semelhanças em suas correlações. O número de correlações significativas entre a precipitação e os casos de dengue desses anos foram maiores nas correlações sem defasagem de um mês no número de casos, todas elas apresentando correlações positivas variando de moderada a muito alta. O maior número de correlações estatisticamente significativas entre temperatura do ar e casos de dengue variou a cada ano entre as correlações sem e com adiantamento de um mês nos casos de dengue. $O$ ano de 2006 teve 6 municípios com resultados significativos para as correlações sem adiantamento de um mês, enquanto que as correlações com o adiantamento de um mês tiveram 5 municípios com correlações significativas estatisticamente. 


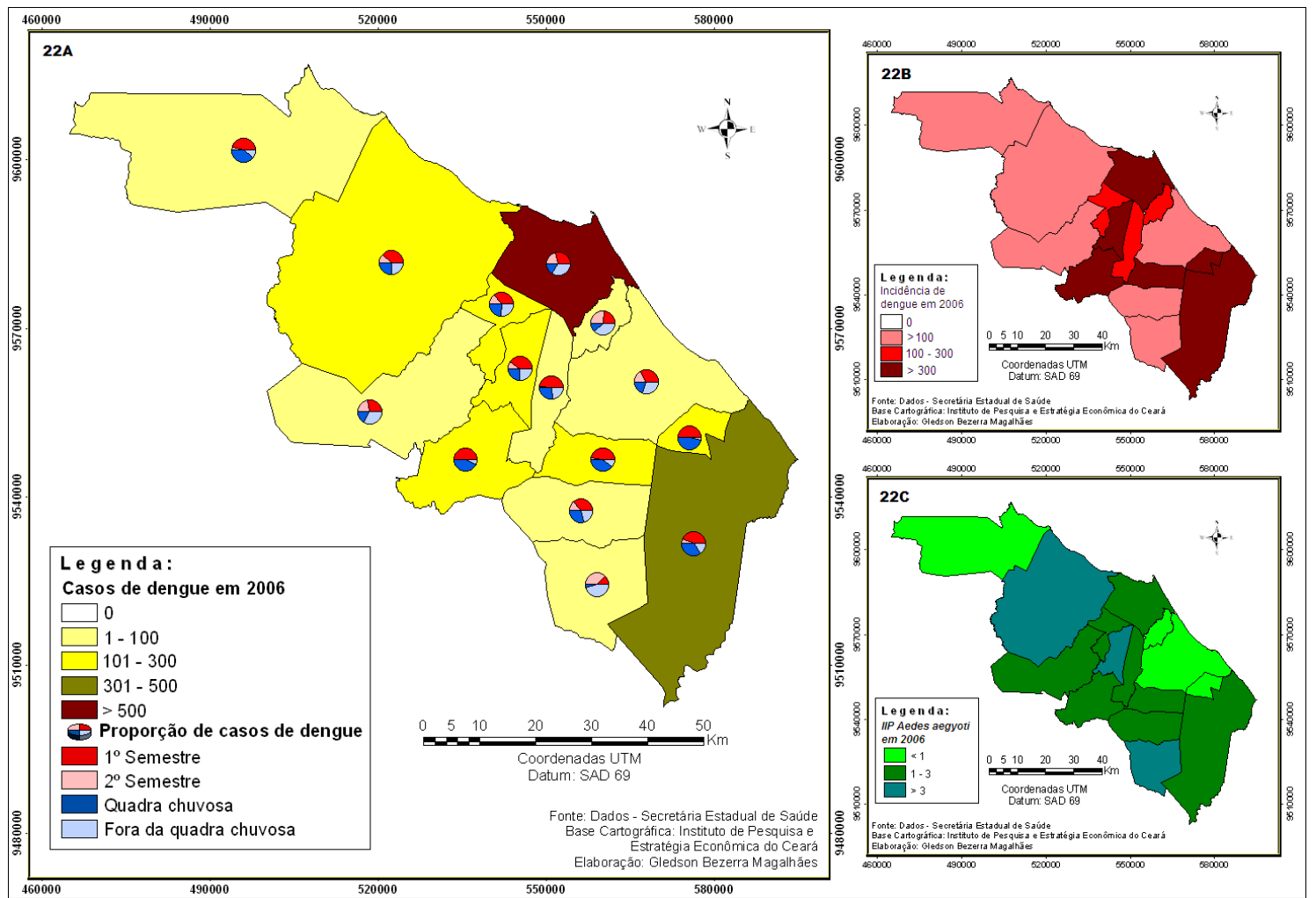

Figura 22 - Mapas do número de casos e incidência de dengue, e índice de infestação predial em 2006

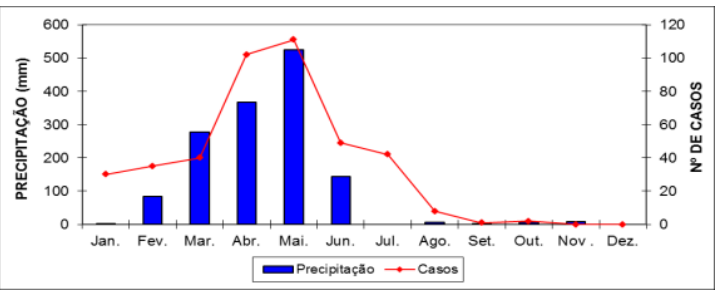

Figura 23 - Precipitação e casos de dengue no município de Cascavel em 2006

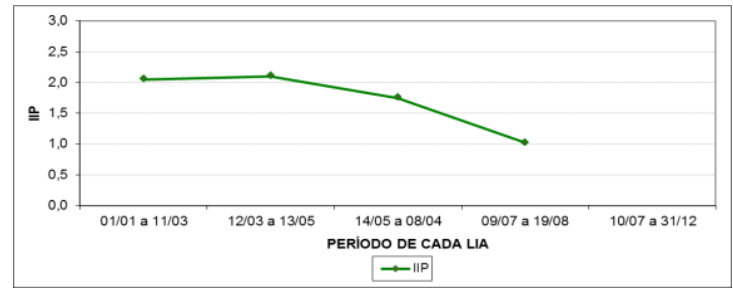

Figura 24 - Índice de Infestação Predial no município de Cascavel em 2006

Em 2007 todos os municípios tiveram casos de dengue. Foram confirmados 12.467 casos, com 5.841 na quadra chuvosa, sendo o mês de maio o de maior número, com 2.258, e o mês de janeiro o de menor quantidade, com 268. No primeiro semestre foram confirmados 8.094 correspondendo a $65 \%$ do total de casos. Todavia os municípios de São Gonçalo do Amarante, Caucaia e Guaiúba apresentaram o maior número de casos no segundo semestre. Fortaleza e Maracanaú tiveram a maior quantidade de casos, 11.447 e 350 respectivamente. O menor número de casos verificou-se em Itaitinga e Pindoretama, ambos com 3 casos (Figura 25A). As incidências foram maiores que 300 somente em Fortaleza, com 470,8 e Pacatuba, com 378,6 (Figura 25B). O IIP foi maior que 3 somente em Chorozinho (Figura 25C). Nesse município houve apenas 29 casos de dengue, e uma incidência 109,1. Essa relação de poucos casos de dengue, incidência e IIP elevados; ocorreu devido ao reduzido número de habitantes no município e a uma baixa circulação viral, apesar de uma alta infestação de Aedes aegypti. Esse fato evidencia a nítida relação entre a densidade demográfica e a propagação da dengue, onde se verifica uma relação direta entre as duas. O comportamento da dengue em Fortaleza também exemplifica o supracitado, onde se verifica uma alta densidade populacional, favorecendo a propagação da dengue mesmo que o IIP seja inferior ao de Chorozinho.

Em 2007, verificou-se uma variedade de condições de mesoescala da atmosfera, iniciando a quadra chuvosa com La Niña forte e Dipolo do Atlântico positivo, e no final da quadra chuvosa configura-se o El Niño fraco com Dipolo do Atlântico negativo. Observou-se também um comportamento pluviométrico bastante diferenciado espacialmente, com postos marcando uma tipologia de ano muito seco a chuvoso. Todavia, temporalmente, verifica-se um comportamento pluviométrico característico da série estudada com os maiores totais 
pluviométricos se concentrando na quadra chuvosa, com totais mensais de chuva crescentes até o mês de abril, decrescendo em maio e junho. O comportamento da dengue na maioria dos municípios acompanhou a quadra chuvosa, todavia nem sempre correspondendo ao mês mais chuvoso. As figuras 26 e 27 apresentam o que ocorreu em Maracanaú, onde se observa uma quantidade crescente de casos a partir do início da quadra chuvosa, entrando em declínio no mês de maio quando as chuvas diminuem gradativamente, ocorrendo o mesmo para o IIP. Esse comportamento predominou entre os municípios sendo exceção Chorozinho e Caucaia. Neles verificou-se um comportamento mensal de casos de dengue similar, tendo o maior número de casos em julho e não correspondendo o maior número de casos com o IIP mais elevado, como mostram as figuras 28 e 29 para Caucaia.

Nas correlações entre a precipitação e o numero de casos de dengue, no ano de 2007, 6 municípios tiveram resultados significativos nas correlações sem defasagem de um mês, com correlações positivas moderadas a fortes. Nenhum município apresentou correlação significativa nos cálculos com defasagem. As correlações entre os casos de dengue e a temperatura do ar tiveram 4 correlações significativas para os cálculos sem defasagem e 4 correlações significativas para cálculos com defasagem, todas elas marcando correlações negativas moderadas a fortes.
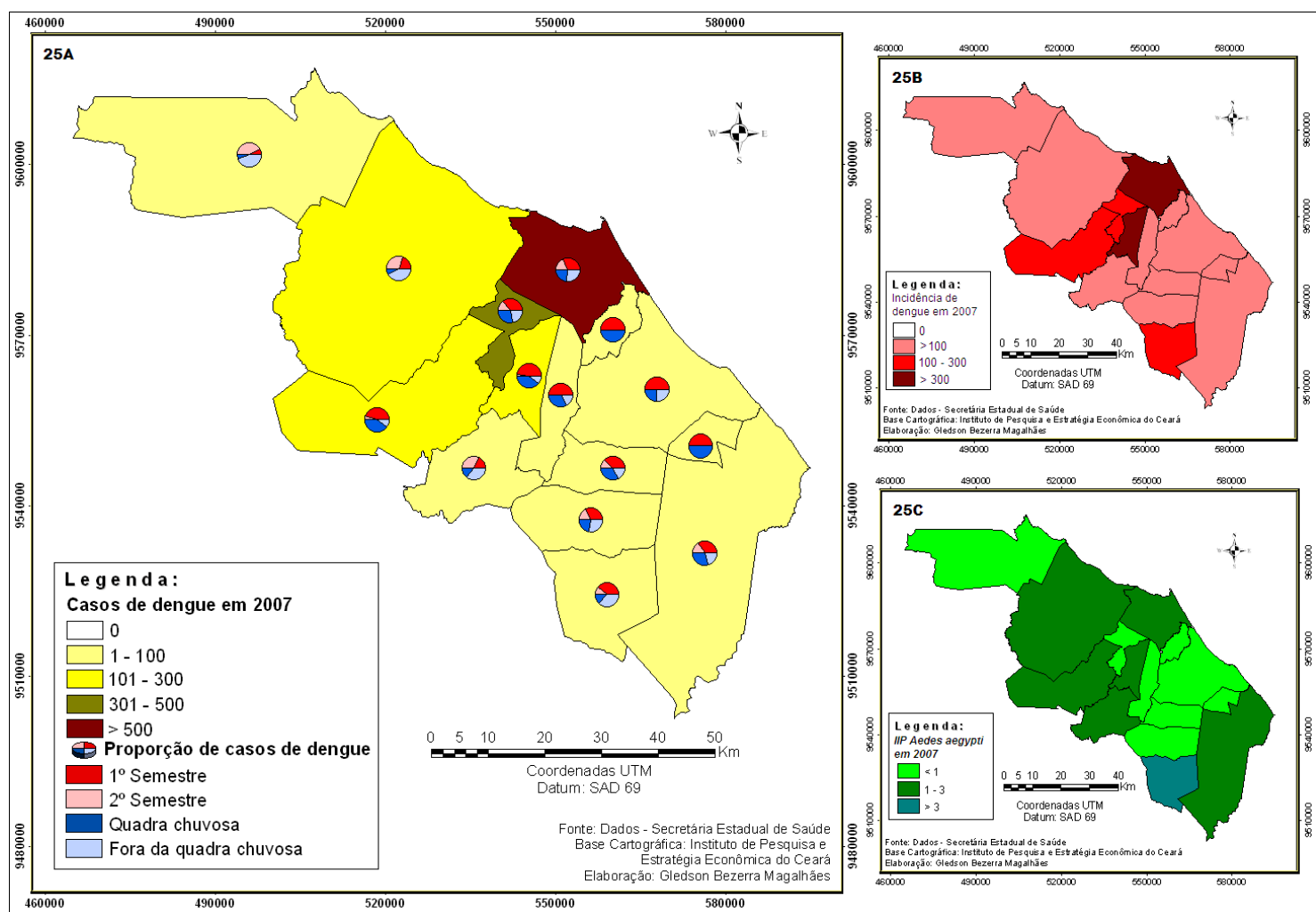

Figura 25 - Mapas do número de casos e incidência de dengue, e índice de infestação predial em 2007

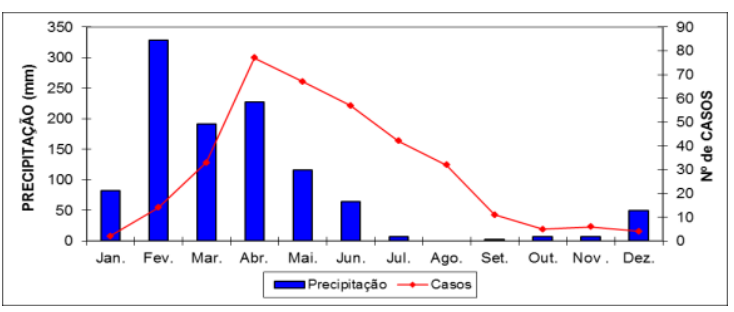

Figura 26 - Precipitação e casos de dengue no município de Maracanaú em 2007

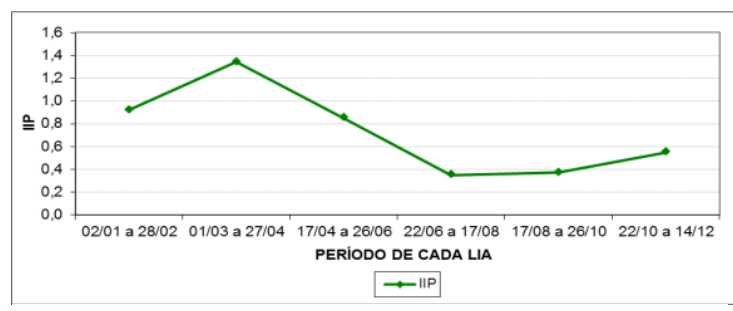

Figura 27 - Índice de Infestação Predial no município de Maracanaú em 2007 


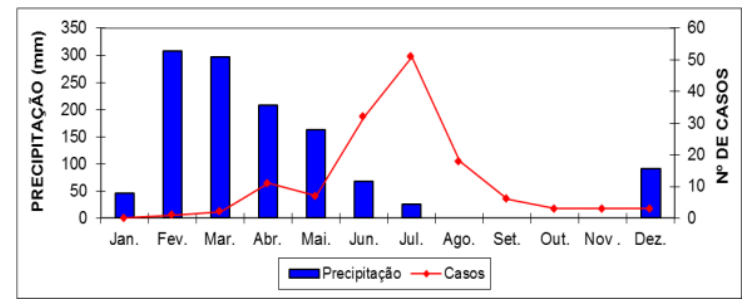

Figura 28 - Precipitação e casos de dengue no município de Caucaia em 2007

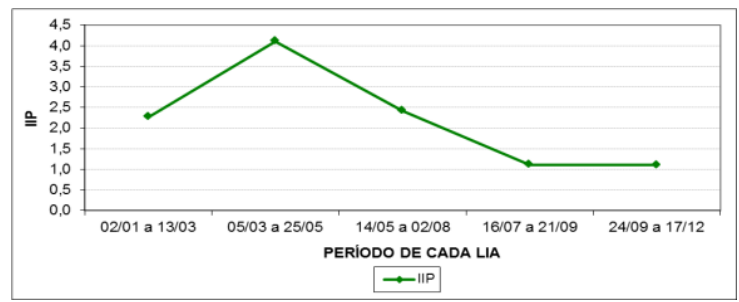

Figura 29 - Índice de Infestação Predial no município de Caucaia em 2007

No ano de 2008, ocorreu a maior quantidade de casos de dengue do período estudado, confirmando 36.120 casos, com maior número em Fortaleza, apresentando 33.845 casos e uma incidência de 1368.2, sendo a maior epidemia deste município entre os anos estudados. Fortaleza concentrou $93,7 \%$ dos casos da RMF, evidenciando que nem todos os municípios tiveram epidemia de dengue neste ano. A maior quantidade de casos em todos os municípios ocorreu no primeiro semestre, representando ao todo $94,4 \%$ dos casos da RMF, com $80,6 \%$ ocorrendo na quadra chuvosa. O mês de abril concentrou a maioria dos casos exceto em Pindoretama que apresentou a maior quantidade de casos em maio. O mês com menos casos foi dezembro, registrando 137 casos dos quais 134 foram em Fortaleza e 3 em São Gonçalo do Amarante. Somente Fortaleza e Caucaia apresentaram acima de 500 casos. São Gonçalo do Amarante, Maracanaú e Cascavel tiveram acima de 100 casos (Figura 30A). A menor quantidade de casos ocorreu em Pindoretama com 12 casos. Incidências acima de 300 foram verificadas em São Gonçalo do Amarante, Fortaleza e Cascavel (Figura 30B). Apenas Pacatuba apresentou IIP acima de 3 (Figura 30C). O município de São Gonçalo do Amarante, apesar de ter tido uma alta incidência de casos de dengue, apresentou um IIP abaixo de 1, mostrando que houve uma intensa circulação do vírus entre os mosquitos vetores da dengue, e devido a sua pequena população em relação ao outros municípios como Caucaia, Fortaleza e Maracanaú, apresentou menor número de casos.

A grande quantidade de casos ocorrida no primeiro semestre de 2008 , ocasionadas pelos sorotipos 2 e 3, principalmente na quadra chuvosa, seguiu o comportamento pluviométrico do ano, onde apesar da irregular distribuição espacial das chuvas, com postos marcando tipologia muito seco a chuvoso, teve um comportamento temporal habitual, com a concentração de chuvas no primeiro semestre e os maiores volumes na quadra chuvosa. Na maioria dos municípios, a maior quantidade de casos em abril, assim como a evolução da infestação por Aedes aegypti, condiz com as crescentes chuvas de fevereiro e março com picos pluviométricos em abril, como mostra a figura 31 e 32 para o município de Caucaia.

$\mathrm{O}$ ano de 2008 apresentou 12 municípios com correlações significativas com valores positivos de forte a muito fortes nos cálculos sem defasagem de um mês entre a precipitação e os casos de dengue. Para os cálculos com defasagem foi verificado 3 correlações significativas, marcando valores positivos. Nas correlações entre a temperatura do ar a casos de dengue foram encontrados 6 municípios com resultados significativos estatisticamente para os dois tipos de correlação, entretanto com 2 municípios diferentes em cada tipo de correlação, com valores negativos variando de correlações moderadas a muito fortes. 


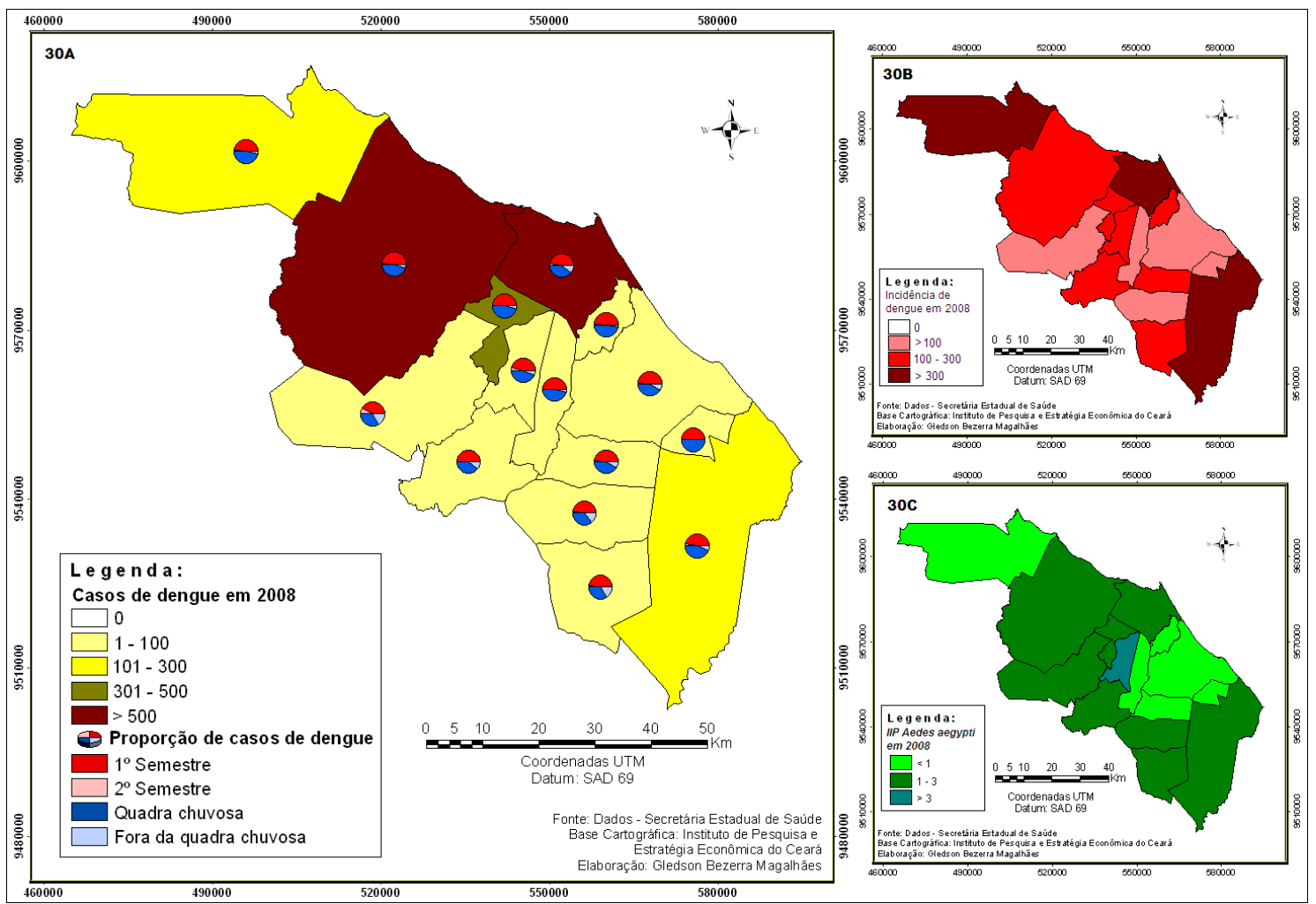

Figura 30 - Mapas do número de casos e incidência de dengue, e índice de infestação predial em 2008

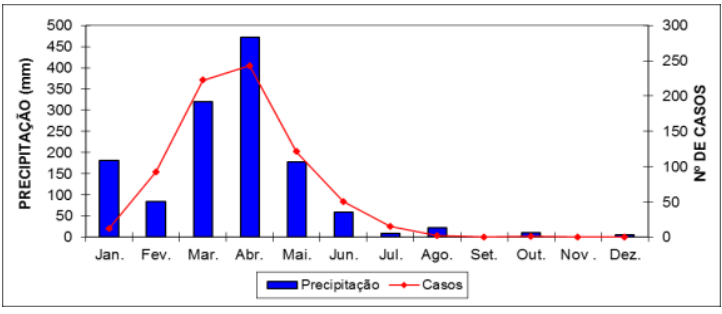

Figura 31 - Precipitação e casos de dengue no município de Caucaia em 2008

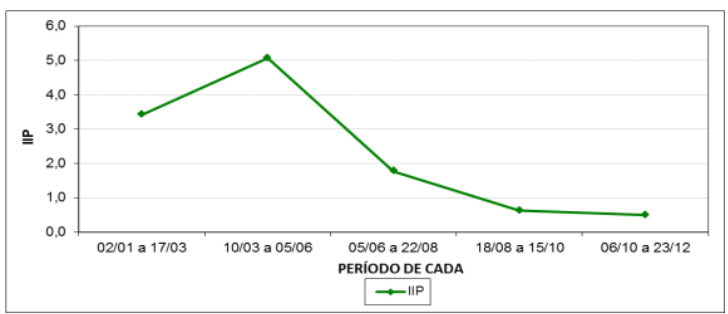

Figura 32 - Índice de Infestação Predial no município de Caucaia em 2008

O ano de 2009 foi o segundo menor em número de casos de dengue, confirmando 4.179 casos, todos ocasionados pelos vírus do tipo 2 . No primeiro semestre ouve $88,4 \%$ dos casos, com maior concentração na quadra chuvosa, onde o mês de março teve a maior quantidade, 1.602 casos, ao contrário do mês de agosto que apresentou a menor quantidade, com 61 casos, sendo 60 em Fortaleza. Nos meses de julho e dezembro Fortaleza concentra a grande maioria de casos; e em setembro, outubro e novembro somente nesse município confirmaram-se casos de dengue. Os municípios de Chorozinho, Guaiúba, Itaitinga e Pindoretama não tiveram casos de dengue em 2009 e o restante dos municípios, com exceção de Fortaleza, tiveram menos de 100 casos (Figura 33A). Excluindo Fortaleza, que concentrou $99 \%$ dos casos, Maracanaú foi o município que apresentou a maior quantidade de casos, 12. Somente em Fortaleza verificou-se incidência acima de 100 e nenhum município apresentou IIP acima de 3 (Figuras 33B e 33C). Chorozinho e Guaiúba, apesar de apresentarem IIP de estado de alerta, não confirmaram nenhum caso de dengue, evidenciando a baixa ou a ausência de circulação do vírus da dengue nesses municípios.

No ano de 2009, teve a maior quantidade de chuvas dos anos em estudo, ocasionado pela configuração do Dipolo Negativo do Atlântico garantindo o deslocamento da Zona de Convergência Intertropical (ZCIT) para o sul da linha do equador e a atuação da La Niña no final da quadra chuvosa. O oposto ocorre com os casos de dengue, onde se verificou 0 segundo ano com menor quantidade de casos, superando apenas o ano de 2004. A ausência de casos nesse ano é uma característica dos anos que sucederam anos epidêmicos e que não há introdução de um novo sorotipo da dengue. Nesse ano o único vírus que causou dengue foi 
o sorotipo 2. A grande concentração de casos em Fortaleza evidencia a baixa circulação do vírus entre os outros municípios. Mesmo com a redução de casos em $88,5 \%$ se comparado ao ano anterior, o comportamento temporal da dengue foi similar a 2008, evidenciando uma sazonalidade dos casos, com o maior número no primeiro semestre, principalmente na quadra chuvosa, acompanhando a infestação do Aedes aegypti e o regime pluviométrico.

Para o ano de 2009 nas correlações entre a precipitação e os casos de dengue, 4 municípios tiveram correlações significativas estatisticamente sem o adiantamento de um mês na quantidade de casos, e 2 municípios com correlações significativas com o adiantamento de um mês, todas com valores positivos e variando de moderada a muito alta. Nas correlações entre temperatura do ar e casos de dengue, apenas duas correlações significativas foram verificadas, ambas com o adiantamento de um mês na quantidade de casos de dengue, demarcando correlação alta com valores negativos.

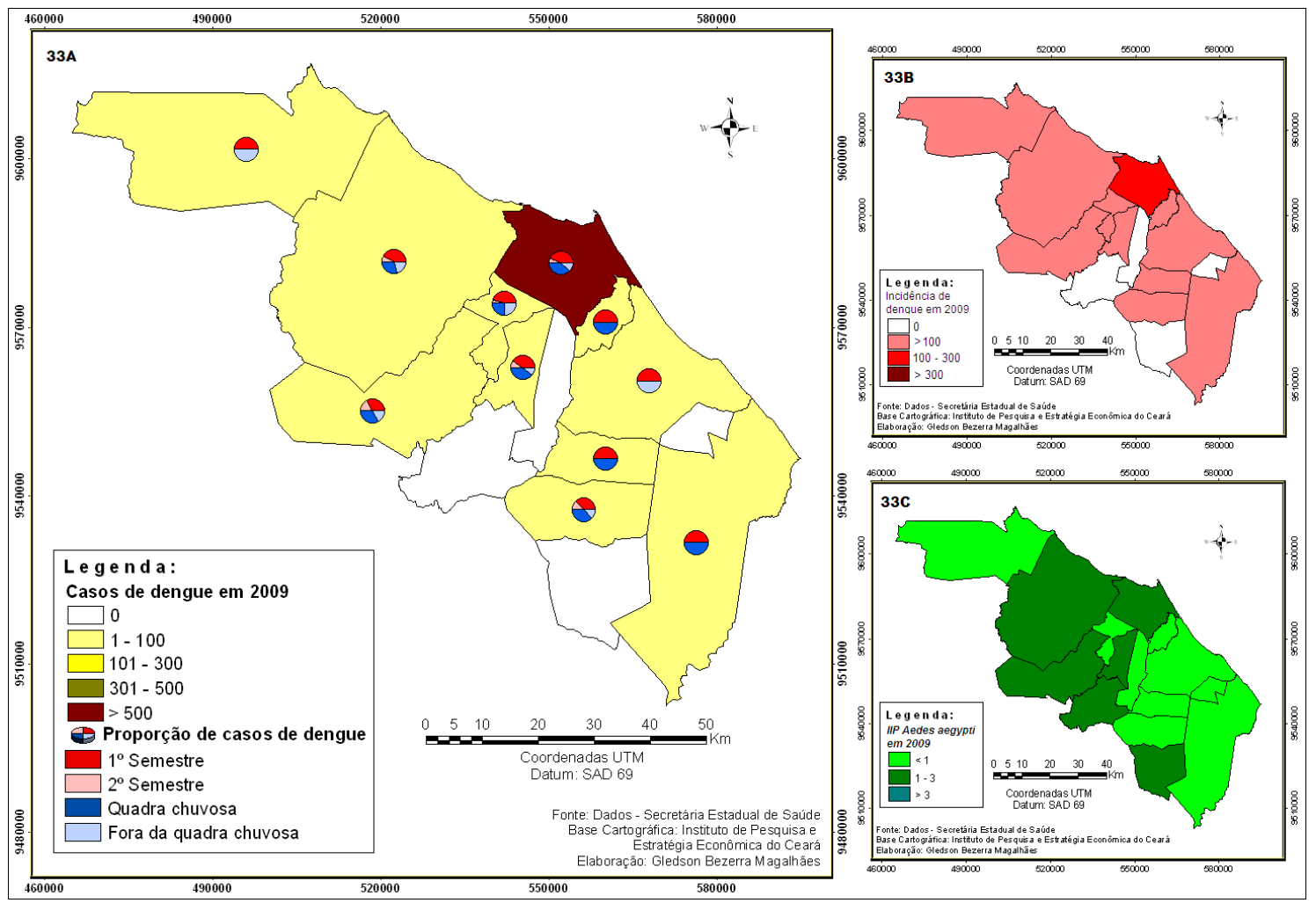

Figura 33 - Mapas do número de casos e incidência de dengue, e índice de infestação predial em 2009

\section{CONSIDERAÇÕES FINAIS}

De forma geral observa-se que em anos de grandes quantidades de chuva e homogeneidade espacial da precipitação na quadra chuvosa, a maior quantidade de casos de dengue ocorreu entre um a dois meses depois dos grandes totais pluviométricos, o que não se verifica em anos com poucas precipitações onde a maior quantidade de casos de dengue ocorreu tanto no mês com maior total pluviométricos como em outros meses que tiveram precipitação ou que sucedeu em até 2 meses os picos de chuva.

Nos anos em que ocorreram poucos casos de dengue, observou-se uma aleatoriedade espaçotemporal de seus casos, e aparentemente uma menor relação com os elementos atmosféricos. Já em anos de epidemia, nota-se uma relação mensal mais nítida entre número de casos e precipitação, assim como uma maior similaridade temporal no comportamento da dengue entre os municípios.

As correlações entre número de casos de dengue e temperatura do ar tiveram resultados negativos indicando uma relação inversamente proporcional. Entretanto, destaca-se que essa relação é fortemente influenciada pela precipitação, visto que, apesar das baixas amplitudes térmicas, as temperaturas mais altas se concentram entre os meses de novembro e fevereiro (com médias máximas alcançando $28.8^{\circ} \mathrm{C}$ ), compreendendo o período de menores chuvas 
(novembro e dezembro) e início da quadra chuvosa (fevereiro). As mais baixas temperaturas variam entre abril a agosto, sendo os meses de junho e julho os mais frios (com médias mínimas entre 25,4 e $26,8^{\circ} \mathrm{C}$ ), e o período onde as chuvas decrescem e cessam. Dessa forma apesar das altas e baixas temperaturas ao longo do ano, suas variações mensais não são tão importantes no processo de infestação do Aedes aegypti e na propagação da dengue se considerar ela associada à precipitação. Isso por que a temperatura média do ar apresenta baixas amplitudes térmicas mensais, sendo as médias térmicas mensais mínimas e máximas ótimas para a proliferação do vetor da dengue, logo a precipitação torna-se o diferencial na dinâmica climática com a doença.

A maior quantidade de correlações estatisticamente significativas verificou-se nas correlações entre a precipitação e os casos de dengue, nas correlações sem o adiantamento de um mês no número de casos de dengue. Já as correlações entre a temperatura do ar e os casos de dengue apresentaram mais resultados significativos com o adiantamento de um mês nos casos de dengue. $\mathrm{O}$ ano de 2008 foi o ano que apresentou o maior número de municípios (12) com correlações significativas entre casos de dengue e precipitação. Enquanto que em 2003 verificou-se a maior quantidade de municípios (7) com correlação significativa entre os casos de dengue e a temperatura do ar.

A variação de municípios que apresentaram correlações estatisticamente significativas a cada ano, nas correlações sem e com adiantamento de um mês nos casos de dengue, evidenciam a dinâmica inexata de dias que se criaram as circunstâncias favoráveis à propagação da doença até a confirmação de casos da mesma. Adotamos o adiantamento de 30 dias, como verificado no estudo de Lima (2003), entretanto esse número de dias pode ser maior ou menor, sendo impossível delimitar uma faixa de tempo precisa, devido à complexidade causal da doença.

Não foi encontrado nenhum padrão de comportamento da dengue ao relacionar os anos com mais correlações significativas e sua tipologia climática. A ausência de um padrão de comportamento se deve a influência de outras variáveis na propagação da dengue, e que não constam nesse estudo. Entretanto pode-se observar a influência da precipitação e da temperatura no processo de propagação da doença.

A intensidade de interação entre o ambiente, o agente, a população de hospedeiros e o vetor determina a dinâmica de transmissão do vírus. Dessa forma a complexa relação entre os fatores de risco ocasionam a propagação da doença em intensidades diferenciadas. Tais fatores ganham amplitude no ambiente urbano, como os fatores sociais (densidade populacional, urbanização mal planejada e densidade habitacional), e os fatores ambientais (morfologia do relevo, temperatura do ar, precipitação, humidade e contato com o hospedeiro). Nessa lógica observa-se uma grande capacidade de adaptação do Aedes aegypti ao ambiente urbano.

Uma cidade mal planejada, com um elevado adensamento habitacional e de grande densidade populacional, favorece o contato com o vetor da doença, além de produzir meios favoráveis a sua reprodução. Associada a esses fatores as características dos elementos climáticos como chuva frequente, elevada humidade e altas temperaturas, produzem condições climáticas excelentes para a proliferação do mosquito.

Diante do exposto advertimos que os estudos e políticas de combate a dengue devem levar em conta as singularidades da cada localidade e as características específicas do perfil epidemiológico de cada região, pois para cada localidade podem-se ter reguladores mais importantes que outros no processo epidêmico da dengue, com determinantes mais críticos a uma epidemia como, por exemplo: a interação entre os quatro sorotipos da doença, ou mesmo o nível de exposição prévia de uma população humana a cada um dos sorotipos.

Visualiza-se a necessidade de se estabelecer períodos padrões para a realização do levantamento de infestação predial em diferentes municípios, proporcionando um banco de dados que possuam as mesmas datas de levantamento. Isso permitiria uma análise mais fidedigna dos dados de forma conjunta. Outro fator a ser levado em conta é a possibilidade de realizar levantamentos de infestação com os períodos sistematicamente definidos, como por exemplo, levantamentos feitos no primeiro semestre e levantamentos feitos no segundo semestre, ou levantamentos feitos na quadra chuvosa e fora dela, visto que hoje as LIAs são feitas de forma aleatória não permitindo um estudo detalhado do conjunto de dados municipais.

Os municípios da RMF devem direcionar trabalhos diferenciados de controle ao mosquito, onde as ocorrências de dengue são mais evidentes, levando em conta a qualidade do trabalho dos 
agentes de controle de vetores. Essas atividades devem preceder os períodos de maior intensidade pluviométrica, visando eliminar a maior quantidade de criadouros e orientar a população quanto aos cuidados que devem ser tomados.

\section{REFERÊNCIAS BIBLIOGRÁFICAS}

BRASIL. Ministério da Saúde. Controle da dengue no Brasil: Estado do Ceará. Brasília: Ministério da Saúde, [200_]. 12p.

BRASIL. Instituto Brasileiro de Geografia e Estatística. Estimativas de População. Instituto Brasileiro de Geografia e Estatística (IBGE), 2009.

BRASIL. Ministério da Saúde. Secretária de Vigilância em Saúde. Boletim Epidemiológico da Dengue, semana $\quad \mathbf{1 4 / 2 0 0 5}$ Disponível em: < http://portal.saude.gov.br/portal/arquivos/pdf/be_dengue_14_2005.pdf>. Acesso em 25 de abril de 2011.

BRASIL. Ministério da Saúde. Secretária de Vigilância em Saúde. Informe Epidemiológico da Dengue de 2009. Disponível em: < http://portal.saúde.gov.br/portal/arquivos/pdf/boletim_dengue_2009.pdf>. Acesso em 1 de Janeiro de 2011.

CEARÁ, Governo do Estado; CEARÁ, Secretária da Saúde. Informe Semanal: Dengue - 08/12/2009. Ceará: Secretária da Saúde, 2009.

CEARÁ, Governo do Estado; CEARÁ, Secretária da Saúde. Informe Semanal: Dengue - 01/04/2011. Ceará: Secretária da Saúde, 01/04/2011.

FORTALEZA, Secretária Municipal de Saúde de Fortaleza. Boletim de Saúde de Fortaleza, Dengue. v.7, no 1 , jan-jun/2003.

GLUBER, D. J. The global emergence/resurgence of arboviral diseases as public health problems. Archives of medical research. México, DF, v. 33, no 4, p. 330-342, 2002.

HALSTEAD, S. B. Epidemiology of dengue and dengue hemorrhagic fever. In : GLUBER, D.J. ; Kuno, G. (Ed.). Dengue and Dengue Hemorrhagic Fever. New York : CAB Inernacional, p. 23-44, 1997.

LIMA, F. J. P. B. Evolução da Dengue em Fortaleza: análise de algumas variáveis. Fortaleza: Gráfica Central, 55p., 2003.

MOURA, M.O. O clima urbano de Fortaleza sob o nível do campo térmico. Fortaleza, 2008. Dissertação de Mestrado (Mestrado em Geografia). Programa de Pós-graduaçãa em Geografia, Universidade Federal do Ceará.

RODHAIN, F.; Rosen, L. Mosquito vectors and dengue virus-vector relationships. In: GLUBER, D. J.; KUNO, G. (Ed.). Dengue and Dengue Hemorrhagic Fever. New York: CAB Internacional, p. 45-60, 1997.

SILVA, L. J. da.; ANGERAMI, R. N. Viroses Emergentes no Brasil. Rio de Janeiro: Editora FIOCRUZ, 132 p., 2008.

SINGHI, S.; KISSOON, N.; BANSAL, A. Dengue and dengue hemorrhagic fever: management issues in an intensive care unit. Jornal de Pediatria, vol. 83, no 2. p. 22-35, 2007.

SIQUEIRA JÚNIOR, J. B. et al. Dengue and dengue hemorrhagic fever, Brazil, 1981-2002. Emerging Infectious Diseases. Atlanta, v. 11, p. 48-53, 2005.

WORLD Health Organization. Strengthening implementation of the global strategy for dengue fever and dengue haemorrhagic fever, prevention and control. Report of the informal consultation, 18-20 October 1999. Geneva: WHO; 1999. 